Sci Transl Med. 2017 May 31; 9(392): . doi:10.1126/scitranslmed.aal3447.

${ }^{\dagger}$ Corresponding author: nb2733@cumc.columbia.edu (N.W.B.); chris.porter@monash.edu (C.J.H.P.); meri.canals@monash.edu (M.C.).

*These authors contributed equally to this work.

SUPPLEMENTARY MATERIALS

www.sciencetranslationalmedicine.org/cgi/content/full/9/392/eaal3447/DC1

Materials and Methods

Fig. S1. Clathrin- and dynamin-dependent $\mathrm{NK}_{1} \mathrm{R}$ endocytosis.

Fig. S2. $\mathrm{NK}_{1} \mathrm{R}$ compartmentalized signaling.

Fig. S3. G protein-dependent $\mathrm{NK}_{1} \mathrm{R}$ signaling in endosomes.

Fig. S4. Nociception and inflammation in vivo.

Fig. S5. $\mathrm{NK}_{1} \mathrm{R}$ endocytosis in spinal neurons in vivo.

Fig. S6. NK 1 R8311 expression and trafficking.

Fig. S7. Uptake of tripartite probes.

Fig. S8. Effects of $\mathrm{NK}_{1} \mathrm{R}$ tripartite antagonists on ERK signaling.

Fig. S9. Synthesis and analysis of Span-Chol and Span-ethyl ester.

Fig. S10. Synthesis and analysis of L-733,060-Chol.

Table S1. Statistical analyses and cell replicates.

Movie S1. Three-dimensional projections of $\mathrm{NK}_{1} \mathrm{R}-\mathrm{IR}$ in neurons in spinal cord slices incubated with Dy4 inact and vehicle.

Movie S2. Three-dimensional projections of $\mathrm{NK}_{1} \mathrm{R}-\mathrm{IR}$ in neurons in spinal cord slices incubated with Dy4 inact and SP.

Movie S3. Three-dimensional projections of $\mathrm{NK}_{1} \mathrm{R}-\mathrm{IR}$ in neurons in spinal cord slices incubated with Dy4 and vehicle.

Movie S4. Three-dimensional projections of NK 1 R-IR in neurons in spinal cord slices incubated with Dy4 and SP.

Movie S5. Three-dimensional projections of $\mathrm{NK}_{1} \mathrm{R}-\mathrm{IR}$ in neurons in spinal cord $10 \mathrm{~min}$ after intraplantar injection of vehicle.

Movie S6. Three-dimensional projections of $\mathrm{NK}_{1} \mathrm{R}-\mathrm{IR}$ in neurons in spinal cord $10 \mathrm{~min}$ after intraplantar injection of capsaicin.

Movie S7. Three-dimensional projections of $\mathrm{NK}_{1} \mathrm{R}-\mathrm{IR}$ in neurons in spinal cord $10 \mathrm{~min}$ after intraplantar injection of capsaicin, with Dy4 injected before capsaicin.

Movie S8. Three-dimensional projections of $\mathrm{NK}_{1} \mathrm{R}-\mathrm{IR}$ in neurons in spinal cord $10 \mathrm{~min}$ after intraplantar injection of capsaicin, with Dy4 inact injected before capsaicin.

Movie S9. Three-dimensional projections of $\mathrm{NK}_{1} \mathrm{R}$-IR in neurons in spinal cord $10 \mathrm{~min}$ after intraplantar injection of capsaicin, with PS2 injected before capsaicin.

Movie S10. Three-dimensional projections of $\mathrm{NK}_{1} \mathrm{R}-\mathrm{IR}$ in neurons in spinal cord $10 \mathrm{~min}$ after intraplantar injection of capsaicin, with PS2 inact injected before capsaicin.

Movie S11. Plasma membrane incorporation and endocytosis of Cy5-cholestanol by HEK293 cells.

Movie S12. Lack of uptake of Cy5-ethyl ester by HEK293 cells.

Movie S13. Time lapse images showing FRET between SNAP-549-NK 1 R and Cy5-Chol.

Movie S14. Animation showing SP-induced assembly of endosomal signaling platform for pain transmission.

References (37-54)

Author contributions: D.D.J. analyzed $\mathrm{NK}_{1} \mathrm{R}$ trafficking; T.L. studied nociception, inflammation, and motor functions; M.L.H. designed and completed FRET analyses of compartmentalized signaling; N.A.V. studied subcellular trafficking of tripartite probes and FRET analysis of probe/receptor interactions; W.L.I. analyzed excitation of spinal neurons by electrophysiology; Q.N.M. studied subcellular trafficking of tripartite probes; D.P.P. examined $\mathrm{NK}_{1} \mathrm{R}$ trafficking by confocal microscopy; T.Q. synthesized and purified tripartite probes; L.A. synthesized and purified tripartite probes; J.C. synthesized and purified tripartite probes; C.K.H. analyzed transcription; N.B. synthesized and purified fluorescent SP; J.S.S. designed tripartite probes; M.J.S. conceived and designed the studies to use tripartite probes to therapeutically target endosomal receptors; B.G. designed tripartite probes; A.M. designed and synthesized inhibitors of endocytosis and inactive control analogs; P.J.R. designed and characterized inhibitors of endocytosis; V.E. designed and prepared cationic liposome and anionic polymer adjuvant for in vivo delivery of siRNA; R.N. measured neuropeptide release from spinal cord; S.M. measured neuropeptide release from spinal cord; P.G. conceived, designed, and analyzed studies to examine neuropeptide release from nociceptors; G.A.H. conceived the studies; M.J.C. conceived, designed, and analyzed studies of excitation of spinal neurons; C.J.H.P. conceived and designed the studies to use tripartite probes to therapeutically target endosomal receptors; M.C. conceived, designed, and completed all BRET analyses of subcellular $\mathrm{NK}_{1} \mathrm{R}$ trafficking and $\mathrm{G}$ protein activation; and N.W.B. conceived the studies, designed experiments, interpreted the results, and wrote the manuscript.

Materials and data availability: Plasmids encoding the FRET biosensors Epac-camps are available from M. J. Lohse under a material transfer agreement with the University of Wurzburg. Plasmids encoding the FRET biosensors cytoplasmic EKAR and nuclear EKAR are available under a material transfer agreement with Addgene. Dy4 is available from A.M. under a material transfer agreement with the University of Newcastle.

Competing interests: Work at N.W.B.'s laboratory was funded, in part, by Takeda Pharmaceuticals Inc. N.W.B. has filed a patent for use of lipidation to target GPCRs in endosomes. All other authors declare that they have no competing interests. 


\title{
Neurokinin 1 receptor signaling in endosomes mediates sustained nociception and is a viable therapeutic target for prolonged pain relief
}

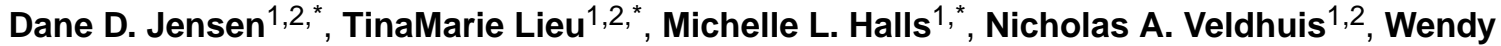 \\ L. Imlach ${ }^{3}$, Quynh N. Mai ${ }^{1,2}$, Daniel P. Poole ${ }^{1,2}$, Tim Quach ${ }^{1,2}$, Luigi Aurelio ${ }^{1,2}$, Joshua \\ Conner $^{1,2}$, Carmen Klein Herenbrink ${ }^{1,2}$, Nicholas Barlow ${ }^{1}$, Jamie S. Simpson ${ }^{1}$, Martin J. \\ Scanlon ${ }^{1}$, Bimbil Graham ${ }^{1}$, Adam McCluskey ${ }^{4}$, Phillip J. Robinson ${ }^{5}$, Virginie Escriou ${ }^{6}$, \\ Romina Nassini ${ }^{7}$, Serena Materazzi ${ }^{7}$, Pierangelo Geppetti ${ }^{7}$, Gareth A. Hicks ${ }^{8}$, Macdonald J. \\ Christie $^{3}$, Christopher J. H. Porter ${ }^{1,2, \dagger}$, Meritxell Canals ${ }^{1,2, \dagger}$, and Nigel W. Bunnett ${ }^{1,2,9,10, \dagger}$ \\ ${ }^{1}$ Monash Institute of Pharmaceutical Sciences, Monash University, Parkville, Victoria 3052 , \\ Australia \\ ${ }^{2}$ Australia Research Council Centre of Excellence in Convergent Bio-Nano Science and \\ Technology, Monash University, Parkville, Victoria 3052, Australia \\ ${ }^{3}$ Discipline of Pharmacology, University of Sydney, New South Wales 2006, Australia \\ ${ }^{4}$ School of Environmental and Life Sciences, University of Newcastle, New South Wales 2308, \\ Australia \\ ${ }^{5}$ Children's Medical Research Institute, University of Sydney, New South Wales 2145, Australia \\ 6Unité de Technologies Chimiques et Biologiques pour la Sante, CNRS UMR8258, INSERM \\ U1022, Université Paris Descartes, Chimie ParisTech, 75006 Paris, France \\ ${ }^{7}$ Department of Health Sciences, Clinical Pharmacology Unit, University of Florence, 6-50139 \\ Florence, Italy \\ ${ }^{8}$ Takeda Pharmaceuticals, Boston, MA 02139, USA \\ ${ }^{9}$ Department of Pharmacology and Therapeutics, University of Melbourne, Victoria 3010, \\ Australia \\ ${ }^{10}$ Departments of Surgery and Pharmacology, Columbia University College of Physicians and \\ Surgeons, Columbia University, 21 Audubon Avenue, Room 209, New York City, NY 10032, USA
}

\section{Abstract}

Typically considered to be cell surface sensors of extracellular signals, heterotrimeric GTPbinding protein (G protein)-coupled receptors (GPCRs) control many pathophysiological processes and are the target of $30 \%$ of therapeutic drugs. Activated receptors redistribute to endosomes, but researchers have yet to explore whether endosomal receptors generate signals that control complex processes in vivo and are viable therapeutic targets. We report that the substance $\mathrm{P}(\mathrm{SP})$ neurokinin 1 receptor $\left(\mathrm{NK}_{1} \mathrm{R}\right)$ signals from endosomes to induce sustained excitation of spinal neurons and pain transmission and that specific antagonism of the $\mathrm{NK}_{1} \mathrm{R}$ in endosomes with membrane-anchored drug conjugates provides more effective and sustained pain relief than conventional plasma membrane-targeted antagonists. Pharmacological and genetic disruption of 
clathrin, dynamin, and $\beta$-arrestin blocked SP-induced $\mathrm{NK}_{1} \mathrm{R}$ endocytosis and prevented SPstimulated activation of cytosolic protein kinase $\mathrm{C}$ and nuclear extracellular signal-regulated kinase, as well as transcription. Endocytosis inhibitors prevented sustained SP-induced excitation of neurons in spinal cord slices in vitro and attenuated nociception in vivo. When conjugated to cholestanol to promote endosomal targeting, $\mathrm{NK}_{1} \mathrm{R}$ antagonists selectively inhibited endosomal signaling and sustained neuronal excitation. Cholestanol conjugation amplified and prolonged the antinociceptive actions of $\mathrm{NK}_{1} \mathrm{R}$ antagonists. These results reveal a critical role for endosomal signaling of the $\mathrm{NK}_{1} \mathrm{R}$ in the complex pathophysiology of pain and demonstrate the use of endosomally targeted GPCR antagonists.

\section{INTRODUCTION}

Whereas acute pain allows avoidance of injury and is essential for survival, chronic pain accompanies disease (for example, inflammatory diseases and neuropathies) and therapy (for example, chemotherapy), afflicts $20 \%$ of individuals at some point of their lives, and is a major cause of suffering (1). The mechanisms that underlie the transition between acute (physiological) and chronic (pathological) pain and that sustain chronic pain are unknown. Current therapies for chronic pain are often ineffective or produce unacceptable side effects. The opioid epidemic, a leading cause of medication-induced death, highlights the need for improved pain therapy (2).

With almost 1000 members in humans, heterotrimeric GTP-binding protein (G protein)coupled receptors (GPCRs) are the largest receptor family, participate in most physiological and pathophysiological processes, are the target of $\sim 30 \%$ of therapeutic drugs (3), and control all steps of pain transmission $(1,4)$. GPCRs at the peripheral terminals of primary sensory neurons detect ligands from inflamed and injured tissues, and GPCRs control the activity of second-order spinal neurons that transmit pain signals centrally. Although GPCRs are a major therapeutic target for chronic pain, most GPCR-targeted drugs for pain have failed in clinical trials, often for unknown reasons $(4,5)$.

GPCRs are conventionally viewed as cell surface receptors that detect extracellular ligands and couple to $\mathrm{G}$ proteins, which trigger plasma membrane-delimited signaling events (second messenger formation, growth factor receptor transactivation, and ion channel regulation). Activated GPCRs associate with $\beta$-arrestins ( $\beta$ ARRs), which uncouple receptors from $G$ proteins and terminate plasma membrane signaling. $\beta$ ARRs also couple receptors to clathrin and adaptor protein- 2 and convey receptors and ligands to endosomes (6). Once considered merely a conduit for GPCR trafficking, endosomes are a vital site of signaling (4, $7,8)$. $\beta$ ARRs recruit GPCRs and mitogen-activated protein kinases to endosomes and thereby mediate endosomal GPCR signaling $(9,10)$. Some GPCRs in endosomes activate $\mathrm{Ga}_{\mathrm{s}} \mathrm{G}$ proteins, suggesting endosomal cyclic adenosine monophosphate (cAMP)-dependent signaling $(11,12)$. GPCR/G protein/ $\beta$ ARR complexes also contribute to sustained signaling by internalized receptors (13). Although a growing number of GPCRs can signal from endosomes, the mechanisms and outcomes of endosomal signaling are incompletely understood, and its relevance to complex pathophysiological processes in vivo is unexplored. 
Drug discovery programs aim to identify ligands for cell surface GPCRs, and whether endosomal GPCRs are a therapeutic target remains to be determined.

We examined the contribution of endocytosis of the neurokinin 1 receptor $\left(\mathrm{NK}_{1} \mathrm{R}\right)$ to substance P (SP)-mediated nociception. Painful stimuli release SP from the central projections of primary sensory neurons in the dorsal horn of the spinal cord, where SP induces endocytosis of the $\mathrm{NK}_{1} \mathrm{R}$ in second-order neurons, which integrate nociceptive signals $(5,14)$. The $\mathrm{NK}_{1} \mathrm{R}$ may also be internalized in pain-sensing regions of the brain of patients with chronic pain $(5,15)$. We hypothesized that endosomal signaling is a critical but unappreciated contributor to pain transmission and that targeting $\mathrm{NK}_{1} \mathrm{R}$ antagonists to sites of endosomal signaling might provide an effective route to pain relief. Thus, the clinical failure of conventional $\mathrm{NK}_{1} \mathrm{R}$ antagonists for the treatment of chronic pain and other chronic conditions associated with $\mathrm{NK}_{1} \mathrm{R}$ endocytosis (5) might relate to their inability to target and antagonize the $\mathrm{NK}_{1} \mathrm{R}$ within multiprotein signalosomes of acidified endosomes.

\section{RESULTS}

\section{Clathrin, dynamin, and $\beta A R R s$ mediate $N_{1} R$ endocytosis}

To quantify $\mathrm{NK}_{1} \mathrm{R}$ endocytosis, we used bioluminescence resonance energy transfer (BRET) to assess $\mathrm{NK}_{1} \mathrm{R}$ proximity to $\beta$ ARRs and resident proteins of plasma membranes (KRAS) and early endosomal membranes (RAB5A) in human embryonic kidney (HEK) 293 cells (fig. S1A). SP (1 or $10 \mathrm{nM}$ ) increased $\mathrm{NK}_{1} \mathrm{R}-\mathrm{RLUC} 8 / \beta \mathrm{ARR} 1 / 2$-yellow fluorescent protein (YFP) BRET (fig. S1, B and C), which is consistent with $\beta$ ARR-mediated $\mathrm{NK}_{1} \mathrm{R}$ endocytosis (16). SP decreased $\mathrm{NK}_{1} \mathrm{R}$-RLUC8/KRAS-Venus BRET and concomitantly increased $\mathrm{NK}_{1} \mathrm{R}$-RLUC8/RAB5A-Venus BRET (fig. S1, D to G), indicating $\mathrm{NK}_{1} \mathrm{R}$ endocytosis. The dynamin inhibitor Dyngo-4a (Dy4) (17), the clathrin inhibitor Pitstop-2 (PS2) (18), and a dominant-negative version of dynamin (K44E) (19) inhibited $\mathrm{NK}_{1} \mathrm{R}$ endocytosis, whereas inactive analogs (Dy4 inact and PS2 inact) and wild-type (WT) dynamin had no effect. Dynamin K44E increased the $\mathrm{NK}_{1} \mathrm{R}-\mathrm{RLUC} 8 / \beta \mathrm{ARR} 1 / 2-\mathrm{YFP}$ BRET, suggesting that dynamin-dependent translocation of the $\mathrm{NK}_{1} \mathrm{R} / \beta \mathrm{ARR}$ from the plasma membrane to endosomes initiates $\mathrm{NK}_{1} \mathrm{R} / \beta \mathrm{ARR}$ dissociation (fig. $\mathrm{S} 1 \mathrm{H}$ ). Dy 4 and PS2 also inhibited endocytosis of fluorescent Alexa Fluor 568-SP in HEK-NK ${ }_{1} \mathrm{R}$ cells, causing retention in punctate structures (fig. S1I). These structures may represent ligand/receptor clusters in invaginated pits in cells treated with Dy4 or at the plasma membrane in cells treated with PS2. Thus, $\beta$ ARRs, clathrin, and dynamin mediate SP-induced $\mathrm{NK}_{1} \mathrm{R}$ endocytosis.

\section{$\mathrm{NK}_{1} \mathrm{R}$ endocytosis mediates SP signaling in subcellular compartments}

To study the link between GPCR endocytosis and signaling in subcellular compartments with high spatiotemporal fidelity, we expressed, in HEK293 cells, the $\mathrm{NK}_{1} \mathrm{R}$ and fluorescence resonance energy transfer (FRET) biosensors for cytosolic (CytoEKAR) or nuclear (NucEKAR) extracellular signal-regulated kinase (ERK) activity, plasma membrane (pmCKAR) or cytosolic (CytoCKAR) protein kinase C (PKC) activity, and plasma membrane (pmEpac2) or cytosolic (CytoEpac2) cAMP (fig. S2A) (20). SP (1 nM) induced a gradual and sustained activation of nuclear ERK (Fig. 1, A to C) and a rapid and sustained 
activation of cytosolic PKC (Fig. 1, D to F) and cAMP (Fig. 1, G to I). SP rapidly and transiently activated cytosolic ERK (fig. S2, B and C), did not affect plasma membrane PKC (fig. S2, D and E), and increased plasma membrane cAMP (fig. S2, F and G). Inhibitors of clathrin (PS2) and dynamin (Dy4) abolished SP stimulation of nuclear ERK (Fig. 1, A to C), cytosolic PKC (Fig. 1, D to F), and cytosolic cAMP (Fig. 1, G to I), indicating a requirement for endocytosis. In contrast, PS2 and Dy4 did not affect SP activation of cytosolic ERK (fig. S2, B and C) or plasma membrane cAMP (fig. S2, F and G), which do not require endocytosis, but amplified plasma membrane PKC activity (fig. S2, D and E). Expression of dynamin K44E, but not dynamin WT, prevented SP stimulation of nuclear ERK (Fig. 1, J to L). Dynamin K44E did not prevent SP stimulation of cytosolic ERK but caused the response to become sustained when compared to dynamin WT (fig. S2, H to J). Knockdown of dynamin-1 and clathrin heavy chain with small interfering RNA (siRNA) (fig. S2, K and L) prevented SP activation of nuclear ERK (Fig. 1, M and N).

Transcription is a major endpoint of GPCR signaling, including activation of nuclear ERK. The $\beta_{2}$-adrenergic receptor signals from endosomes to regulate transcription (21). To investigate the contribution of $\mathrm{NK}_{1} \mathrm{R}$ endocytosis to SP-stimulated transcription, we expressed in HEK-NK ${ }_{1} \mathrm{R}$ cells a reporter encoding secreted alkaline phosphatase (SEAP) under control of the serum response element (SRE) transcription factor. SP (10 nM) stimulated SRE-SEAP secretion after 4 and 24 hours, indicating stimulated transcription (Fig. 1O). Dynamin K44E abolished SP-stimulated transcription at both times. Dynamin K44E reduced the efficacy but not the potency of SP-induced transcription, measured after 24 hours (fig. S2M). Thus, $\mathrm{NK}_{1} \mathrm{R}$ endocytosis is required for $\mathrm{SP}$ stimulation of transcription.

We have previously shown that $\beta$ ARRs mediate $\mathrm{NK}_{1} \mathrm{R}$ endosomal signaling and nuclear ERK activation $(9,22,23)$. To examine the contribution of $G$ proteins to endosomal $\mathrm{NK}_{1} \mathrm{R}$ signaling, we used BRET to study SP-induced trafficking of $\mathrm{Ga}_{\mathrm{q}}$ subunits to early endosomes containing RAB5A. SP $(0.1$ to $10 \mathrm{nM})$ decreased $\mathrm{NK}_{1}$ R-RLUC8/KRAS-Venus and increased $\mathrm{NK}_{1} \mathrm{R}-\mathrm{RLUC} 8 / \mathrm{RAB} 5 \mathrm{~A}-\mathrm{Venus} \mathrm{BRET}$, demonstrating endocytosis, and decreased $\mathrm{Ga}_{\mathrm{q}}-\mathrm{RLUC} 8 / \mathrm{G}_{2}$-Venus BRET, consistent with $\mathrm{G}$ protein activation (Fig. 2, A to $\mathrm{C}$, and fig. S3, A to C). SP increased $\mathrm{Ga}_{\mathrm{q}}-\mathrm{RLUC8/RAB5A-Venus} \mathrm{BRET,} \mathrm{which} \mathrm{indicates}$ $\mathrm{Ga}_{\mathrm{q}}$ translocation to early endosomes that contain the internalized $\mathrm{NK}_{1} \mathrm{R}$ (Fig. 2D and fig. $\mathrm{S} 3 \mathrm{D}$ ). In SP-stimulated cells, $\mathrm{NK}_{1} \mathrm{R}$-immunoreactivity (IR) and $\mathrm{Ga}_{\mathrm{q}}$-IR colocalized with early endosomal antigen 1 (EEA1)-IR (Fig. 2, E and F); IR was detected using immunofluorescence and super-resolution microscopy.

The $\mathrm{Ga}_{\mathrm{q}}$ inhibitor UBO-QIC prevented SP activation of nuclear ERK (Fig. 2G and fig. S3E), which also depends on $\beta$ ARRs and PKC but not on epidermal growth factor receptor transactivation $(9,22,23)$. UBO-QIC, the phospholipase C (PLC) inhibitor U73122, and the $\mathrm{Ca}^{2+}$ chelator EGTA prevented activation of cytosolic PKC (Fig. 2H and fig. S3F), which is consistent with a $\mathrm{Ga}_{\mathrm{q}}$, PLC, and $\mathrm{Ca}^{2+}$-dependent PKC pathway. UBO-QIC, the PKC inhibitor GF109203X, and EGTA, but not the $\mathrm{Ga}_{\mathrm{s}}$ inhibitor NF449, prevented SP generation of cytosolic cAMP (Fig. 2I and fig. S3G), supporting a role for $\mathrm{Ga}_{\mathrm{q}}$-mediated activation of $\mathrm{Ca}^{2+}$-dependent PKC in the generation of cAMP. UBO-QIC did not affect $\mathrm{NK}_{1} \mathrm{R}$ endocytosis (fig. S3H). In addition to inhibiting PKCa (4\% control), GF109203X (Bis-1) also inhibits other kinases (24), which may also contribute to SP signaling. These results 
support the hypothesis that $\mathrm{SP}$ and the $\mathrm{NK}_{1} \mathrm{R}$ signal from endosomes by $\mathrm{Ga}_{\mathrm{q}}$-mediated mechanisms to activate nuclear ERK and cytosolic PKC and cAMP.

\section{Endocytosis mediates sustained SP-evoked excitation of spinal neurons}

The $\mathrm{NK}_{1} \mathrm{R}$ mediates nociceptive transmission in second-order spinal neurons, where painful stimuli induce $\mathrm{SP}$ release, $\mathrm{NK}_{1} \mathrm{R}$ endocytosis, and ERK activation $(5,14,25)$. SP causes persistent $\mathrm{NK}_{1} \mathrm{R}$-dependent excitation of spinal neurons by unknown mechanisms (26). To evaluate whether $\mathrm{NK}_{1} \mathrm{R}$ endosomal signaling mediates this sustained excitation, we made cell-attached patch clamp recordings from $\mathrm{NK}_{1} \mathrm{R}$-positive neurons in lamina I of the dorsal horn in slices of rat spinal cord. SP $(1 \mu \mathrm{M}, 5 \mathrm{~min})$ stimulated $\mathrm{NK}_{1} \mathrm{R}-\mathrm{IR}$ endocytosis in spinal neurons (Fig. 3, A and B, and movies S1 to S4). Brief exposure to SP (1 $\mu \mathrm{M}, 2 \mathrm{~min})$ triggered rapid-onset action potential firing that was sustained after washout (Fig. 3, C to E). Dy4 but not Dy4 inact inhibited $\mathrm{NK}_{1} \mathrm{R}$ endocytosis. Dy4 did not affect the initial onset of SP-induced firing but prevented the sustained response, reducing both the firing rate and firing time, whereas Dy4 inact had no effect. The SP-induced firing rate (events per $2 \mathrm{~min}$, normalized to rate at $2 \mathrm{~min}$ ) was $342.1 \pm 120.7$ with Dy4 and 569.0 \pm 187.6 with Dy4 inact $[P<0.05$, analysis of variance (ANOVA), Sidak's test $]$.

To define the signaling pathway that mediates SP-evoked excitation of spinal neurons, slices were preincubated with inhibitors of mitogen-activated protein kinase kinase (MEK) (U0126), PKC (GF109203X), or vehicle (control). U0126 inhibited the SP-induced firing time of lamina I neurons by $67.5 \pm 8.3 \%$ (control: $10.01 \pm 1.8 \mathrm{~min}, n=10$ cells from eight rats; U0126: $3.2 \pm 0.8 \mathrm{~min}, n=6$ cells from six rats; $P<0.05$, ANOVA, Dunn's test) (Fig. 3 , F to H). GF109203X reduced SP-induced firing time of lamina I neurons by $56.8 \pm 8.2 \%$ (control: $10.01 \pm 1.8 \mathrm{~min}, n=10$ cells from eight rats; GF109203X: $4.33 \pm 0.82 \mathrm{~min}, n=7$ cells from four rats; $P<0.05$, ANOVA, Dunn's test). U0126 and GF109203X reduced the number of SP-stimulated action potentials by $84 \pm 5 \%$ and $61 \pm 15 \%$, respectively, compared to controls.

Dy4 did not affect the generation of excitatory postsynaptic currents (EPSCs) in lamina $\mathrm{I} / \mathrm{II}_{\mathrm{O}}$ neurons in response to primary afferent stimulation (Fig. 3, I and J). PS2 and Dy4 did not affect capsaicin-stimulated release of SP or calcitonin gene-related peptide (CGRP) from segments of mouse dorsal spinal cord (Fig. 3, $\mathrm{K}$ and L). Thus, $\mathrm{NK}_{1} \mathrm{R}$ endocytosis and resultant ERK and PKC signaling mediate sustained SP-induced firing of spinal neurons. The effects of dynamin and clathrin inhibitors in the spinal cord are unrelated to changes in glutaminergic-mediated fast synaptic transmission or the exocytosis of neuropeptides.

\section{Clathrin, dynamin, and $\beta$ ARRs mediate $\mathrm{NK}_{1} \mathrm{R}$ endocytosis and nociception in vivo}

To determine the involvement of dynamin and clathrin in $\mathrm{NK}_{1} \mathrm{R}$ endocytosis in vivo, we injected Dy4, PS2, inactive analogs, or vehicle intrathecally (L3/L4) to rats. After $30 \mathrm{~min}$, vehicle or capsaicin was administered by intraplantar injection. The spinal cord was removed 10 min later, and the $\mathrm{NK}_{1} \mathrm{R}$ was localized by immunofluorescence and confocal microscopy. In vehicle-treated control rats, the $\mathrm{NK}_{1} \mathrm{R}$-IR was mostly at the plasma membrane of lamina I neurons ( $\% \mathrm{NK}_{1} \mathrm{R}-\mathrm{IR}$ within $0.5 \mu \mathrm{m}$ of plasma membrane, $80.7 \pm 1.6$; $n=3$ rats, 6 neurons analyzed per rat) (Fig. 4, A and C, and movie S5). Intraplantar injection 
of capsaicin stimulated $\mathrm{NK}_{1} \mathrm{R}$ endocytosis $(42.1 \pm 5.6 ; P=0.0027$ to control, Student's $t$ test) (movie S6). Intrathecal injection of Dy4 or PS2, but not inactive analogs, inhibited capsaicin-stimulated $\mathrm{NK}_{1} \mathrm{R}$ endocytosis [Dy4 (59.6 \pm 0.2$)$ versus Dy4 inact (49.9 \pm 0.8$), P=$ 0.0004 (Student's $t$ test); PS2 $(69.0 \pm 1.1)$ versus PS2 inact (51.9 \pm 1.3$), P=0.0135$

(Student's $t$ test)] (movies S7 to S10 and Fig. 4, A and C). Painful peripheral stimuli activate ERK in $\mathrm{NK}_{1} \mathrm{R}$-expressing spinal neurons, which contributes to hyperalgesia (25). Intraplantar capsaicin stimulated ERK phosphorylation in lamina I/II dorsal horn neurons (Fig. 4, B and D). Dy4 or PS2 prevented capsaicin-stimulated ERK activation in spinal neurons. Thus, painful stimuli induce clathrin- and dynamin-dependent $\mathrm{NK}_{1} \mathrm{R}$ endocytosis in spinal neurons, which is required for ERK signaling.

Does $\mathrm{NK}_{1} \mathrm{R}$ endocytosis in spinal neurons mediate pain transmission? To evaluate the importance of the $\mathrm{NK}_{1} \mathrm{R}$, clathrin, and dynamin for nociception, we injected vehicle, $\mathrm{NK}_{1} \mathrm{R}$ antagonist SR140,333 (27), Dy4, PS2, or inactive analogs intrathecally (L3/L4) to mice. After $30 \mathrm{~min}$, vehicle or capsaicin was administered by intraplantar injection into one hindpaw. Withdrawal responses were measured to stimulation of the plantar surface of the ipsilateral (injected) and contralateral (noninjected) hindpaws with von Frey filaments, and edema was assessed by measuring thickness of the ipsilateral paw. In vehicle (intrathecal)treated mice, capsaicin caused mechanical allodynia and edema for 4 hours. SR140,333 caused a partial and transient inhibition of capsaicin-induced allodynia, whereas Dy4 and PS2, but not inactive analogs, caused a large and sustained inhibition of allodynia (Fig. 4E and fig. S4A). Paw edema was unaffected, confirming that after intrathecal injection, the drugs act locally in the spinal cord (fig. S4B).

Dy4 and PS2 did not affect withdrawal responses of the contralateral paw or rotarod latency, suggesting normal motor behavior (Fig. 4, F and G). Intrathecal Dy4 also inhibited capsaicin-evoked mechanical allodynia in rat, which supports a role for dynamin in nociception in different species (fig. S4C).

Intrathecal injection of dynamin-1 siRNA knocked down dynamin-1-IR (fig. S4D) and inhibited capsaicin-evoked allodynia after 24 and 48 hours in mice (Fig. 4H and fig. S4E). Intrathecal $\beta$ ARR $1 / 2$ siRNA knocked down $\beta$ ARR1/2 mRNA (fig. S4F) and inhibited capsaicin-evoked allodynia at 36 hours (Fig. 4I). siRNAs did not affect withdrawal responses of the contralateral paw (fig. S4, G and H), consistent with normal motor function.

Endocytosis and subsequent recycling mediate resensitization and sustained signaling of several GPCRs, including the $\mathrm{NK}_{1} \mathrm{R}$ (28). Thus, the antinociceptive actions of endocytic inhibitors could be due to disrupted resensitization of plasma membrane signaling rather than to impaired endosomal signaling. Endothelin-converting enzyme-1, which is coexpressed with the $\mathrm{NK}_{1} \mathrm{R}$ in spinal neurons (22), degrades SP in endosomes and thereby promotes recycling and resensitization of the $\mathrm{NK}_{1} \mathrm{R}(29)$. However, intrathecal injection of SM-19712, an inhibitor of endothelin-converting enzyme- 1 that prevents $\mathrm{NK}_{1} \mathrm{R}$ recycling and resensitization (29), had no effect on capsaicin-induced allodynia (Fig. 4J). These results suggest that the analgesic actions of endocytic inhibitors are unrelated to disrupted resensitization. Consistent with a role for $\mathrm{NK}_{1} \mathrm{R}$ endocytosis and $\beta \mathrm{ARR}$ in SP-evoked 
nuclear ERK signaling (9), intrathecal MEK inhibitor U0126 inhibited capsaicin-evoked allodynia (Fig. 4K) (25).

The effects of inhibitors of dynamin and clathrin on non-inflammatory and inflammatory pain were examined. Intrathecal injection of Dy4 and PS2 blunted both the early (noninflammatory) and late (inflammatory) phases of the nocifensive response to intraplantar formalin (Fig. 4L). When injected intrathecally 36 hours after intraplantar injection of complete Freund's adjuvant (CFA), which causes sustained inflammatory pain, inhibitors of dynamin and clathrin reversed preexisting mechanical hyperalgesia (Fig. 4M). The $\mathrm{NK}_{1} \mathrm{R}$ was robustly internalized in spinal neurons of mice after intraplantar injection of capsaicin, formalin, and CFA (fig. S5, A to D). Intrathecal injection of Dy4 prevented capsaicin- and formalin-induced $\mathrm{NK}_{1} \mathrm{R}$ endocytosis and reversed CFA-induced $\mathrm{NK}_{1} \mathrm{R}$ endocytosis. These results suggest that clathrin and dynamin mediate pain-evoked endocytosis of $\mathrm{NK}_{1} \mathrm{R}$ in spinal neurons, which is required for nociception.

\section{Disruption of $N K_{1} R / \beta A R R$ interactions inhibits $N_{1} R$ endocytosis and nociception in vivo}

To substantiate involvement of $\mathrm{NK}_{1} \mathrm{R}$ endocytosis in nociception, we devised a pharmacological approach to inhibit $\mathrm{NK}_{1} \mathrm{R} / \beta \mathrm{ARR}$ interactions and $\mathrm{NK}_{1} \mathrm{R}$ endocytosis. $\mathrm{G}$ protein receptor kinases (GRKs) phosphorylate $\mathrm{S} / \mathrm{T}$-rich regions in the $\mathrm{C}$ terminus of GPCRs, which interact with $\beta$ ARRs (30). A deletion mutant $\mathrm{NK}_{1} \mathrm{R} \delta 311$ lacks the $\mathrm{C}$ terminus and corresponds to a naturally occurring $\mathrm{NK}_{1} \mathrm{R}$ variant (Fig. $5 \mathrm{~A}$ ) (5). $\mathrm{NK}_{1} \mathrm{R} \delta 311$ was normally expressed at the plasma membrane of HEK293 cells but did not associate with $\beta$ ARRs or internalize (Fig. 5, B and C, and fig. S6, A to C). In HEK-NK ${ }_{1}$ R 8311 cells, SP stimulated cytosolic but not nuclear ERK and did not affect transcription activity, consistent with endocytosis-dependent nuclear ERK signaling and transcription (Fig. 5, D and E). Peptides corresponding to predicted phosphorylation sites in the $\mathrm{C}$ terminus of mouse $\mathrm{NK}_{1} \mathrm{R}$ were conjugated to membrane-penetrating Tat peptide (Fig. 5A). A combination of three peptides inhibited SP-induced $\mathrm{NK}_{1} \mathrm{R}$-RLUC8/ $\beta$ ARR2-YFP BRET and prevented SPinduced $\mathrm{NK}_{1} \mathrm{R}$ endocytosis, compared to a control peptide, suggesting effective disruption of $\mathrm{NK}_{1} \mathrm{R} / \beta \mathrm{ARR}$ interactions (Fig. 5, F and G). When injected intrathecally, inhibitors of $\mathrm{NK}_{1} \mathrm{R} / \beta \mathrm{ARR}$ interactions suppressed capsaicin-evoked allodynia and formalin-induced nociceptive behavior and reversed CFA-induced hyperalgesia (Fig. 5, $\mathrm{H}$ to J). Together, these results support a role for $\beta A R R$-mediated $\mathrm{NK}_{1} \mathrm{R}$ endocytosis and endosomal signaling in nociception.

\section{Lipid conjugation delivers $\mathrm{NK}_{1} \mathrm{R}$ antagonists to endosomes and selectively blocks sustained endosomal signals}

We observed that clathrin, dynamin, and $\beta A R R$ inhibitors and siRNA, including selective inhibitors of $\mathrm{NK}_{1} \mathrm{R} / \beta \mathrm{ARR}$ interactions, suppress $\mathrm{SP}$-induced $\mathrm{NK}_{1} \mathrm{R}$ endocytosis, compartmentalized signaling, transcription, and neuronal excitability, and have antinociceptive actions. These findings support the hypothesis that endosomal $\mathrm{NK}_{1} \mathrm{R}$ signaling underlies sustained neuronal excitation and nociception. Thus, selective antagonism of endosomal receptors could be an effective treatment for pain. To investigate this possibility and to provide direct evidence for the importance of endosomal signaling for 
nociception, we devised an approach to deliver and concentrate GPCR antagonists in early endosomes.

Lipid conjugation anchors drugs at membrane surfaces and promotes endosomal delivery (31). We synthesized tripartite probes composed of cholestanol (Chol; promotes membrane insertion and anchoring) or ethyl ester (control; no membrane anchoring), a flexible polyethylene glycol (PEG) linker, and a cargo of either cyanine 5 (Cy5) for localization or spantide I (Span), a peptidic membrane-impermeant $\mathrm{NK}_{1} \mathrm{R}$ antagonist (Fig. 6A) (32). In addition, we synthesized a probe incorporating Span and Cy5 (Span-Cy5-Chol). When incubated with HEK293 cells, Cy5-Chol inserted into the plasma membrane within 5 min, whereas Cy5-ethyl ester remained entirely extracellular (Fig. 6B and movies S11 and S12). After 4 hours of continuous incubation, Cy5-Chol was concentrated in RAB5A-positive early endosomes, although Cy5-Chol was also detected at the plasma membrane (Fig. 6C). When incubated with HEK-NK $\mathrm{N}_{1} \mathrm{R}$-green fluorescent protein (GFP) cells for 4 hours, Cy5Chol also colocalized with $\mathrm{NK}_{1} \mathrm{R}$-GFP in endosomes (cells were stimulated with SP to induce $\mathrm{NK}_{1} \mathrm{R}$ endocytosis) (Fig. 6C). When HEK-NK ${ }_{1} \mathrm{R}-\mathrm{GFP}$ cells were pulse-incubated with Cy5-Chol for 30 or 60 min, washed, and allowed to recover for 4 hours, Cy5-Chol was gradually removed from the plasma membrane and accumulated in $\mathrm{NK}_{1} \mathrm{R}$-GFP-positive endosomes, although some probe remained at the plasma membrane (fig. S7, A and C). Cy5-ethyl ester was not taken up by cells after pulse incubation (fig. S7B). Quantification of Cy5-Chol uptake after a 30-min pulse incubation indicated that $69 \%$ of cell-bound probe was internalized at 4 hours and 79\% was internalized at 8 hours after washing (fig. S7D). After pulse incubation, Cy5-Span-Chol trafficked to $\mathrm{NK}_{1} \mathrm{R}-\mathrm{GFP}-$ positive endosomes (Fig. 6C). Dy4 inhibited uptake of Chol-conjugated tripartite probes, consistent with constitutive dynamin-mediated endocytosis (fig. S7E).

We used FRET to quantify association of tripartite probes with the $\mathrm{NK}_{1} \mathrm{R}$ in endosomes. $\mathrm{NK}_{1} \mathrm{R}$ with extracellular N-terminal SNAP-Tag was expressed in HEK293 cells, and cell surface $\mathrm{NK}_{1} \mathrm{R}$ was labeled with membrane-impermeant SNAP-Surface-549 (SNAP-549). SP (10 nM, $30 \mathrm{~min}$ ) evoked translocation of SNAP-549-NK R $_{1}$ to endosomes (Fig. 6D). Cells were treated with Cy5-Chol, and FRET between SNAP-549-NK $\mathrm{N}_{1}$ and Cy5-Chol was measured in regions of interest within the cytosol. Cy5-Chol/SNAP-549-NK ${ }_{1} \mathrm{R}$ FRET was detected after $5 \mathrm{~min}$ and increased for $60 \mathrm{~min}$ (Fig. 6, D and E, and movie S13). FRET was not detected in control cells lacking $\mathrm{NK}_{1} \mathrm{R}$ (Fig. 6E).

Span-Chol antagonized SP [3 nM; $80 \%$ effective concentration $\left.\left(\mathrm{EC}_{80}\right)\right]$-stimulated $\mathrm{Ca}^{2+}$

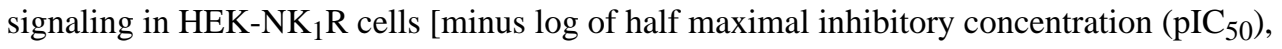
$8.23 \pm 0.21$ (Span) and $8.44 \pm 0.29$ (Span-Chol)] and thus retained activity. Because the tripartite probe was concentrated in endosomes after 4 hours, we examined $N_{1} R$ endosomal signaling 4 hours after preincubation with antagonists. When HEK-NK $\mathrm{N}_{1} \mathrm{R}$ cells were preincubated with Span-Chol, Span, or SR140,333 for $30 \mathrm{~min}$ and then immediately challenged with SP, all antagonists blocked nuclear ERK (Fig. 6, F and H) and cytosolic ERK (fig. S8, A and C) activity, indicating effective antagonism of cell surface $\mathrm{NK}_{1} \mathrm{R}$. When cells were pulse-incubated with antagonists for $30 \mathrm{~min}$, washed, and stimulated with SP 4 hours later (to allow lipidated antagonists to concentrate in endosomes), Span-Chol alone inhibited nuclear ERK (derives from endosomal $\mathrm{NK}_{1}$ R) (Fig. 6, G and H), and no antagonist 
inhibited cytosolic ERK (derives from plasma membrane $\mathrm{NK}_{1} \mathrm{R}$ ) (fig. S8, B and C). SpanChol also prevented SP-induced transcription. $\mathrm{HEK}-\mathrm{NK}_{1} \mathrm{R}$ cells were incubated with Span or Span-Chol for $30 \mathrm{~min}$, washed, recovered for 4 hours, and then stimulated with SP for 20 hours. Span-Chol abolished SP-stimulated SRE-SEAP secretion (derives from endosomal $\mathrm{NK}_{1} \mathrm{R}$ ), whereas unconjugated Span was ineffective (Fig. 6I). However, when continuously incubated with antagonists, both Span-Chol and Span inhibited transcription. Span-Chol did not affect isoprenaline-induced activation of nuclear ERK, which is mediated by the endogenous $\beta_{2}$-adrenergic receptor (fig. S8D). Thus, the effects of tripartite antagonists are not mediated by a nonspecific disruption of endosomal signaling.

The results show that lipid conjugation promotes the effective delivery and retention of antagonists to endosomes containing the $\mathrm{NK}_{1} \mathrm{R}$. After pulse incubation, Span-Chol caused sustained and selective antagonism of endosomal but not plasma membrane $\mathrm{NK}_{1} \mathrm{R}$. Unconjugated Span and SR140,333, a potent small-molecule antagonist, were unable to effectively inhibit persistent $\mathrm{NK}_{1} \mathrm{R}$ signaling in endosomes.

\section{Endosomally targeted $\mathrm{NK}_{1} \mathrm{R}$ antagonists block nociception}

To assess whether antagonism of the endosomal $\mathrm{NK}_{1} \mathrm{R}$ blocks sustained SP-induced excitation of spinal neurons, we incubated slices of rat spinal cord with Span-Chol or Span for $60 \mathrm{~min}$, washed them, and challenged them with SP 60 min later. In vehicle- or Spantreated slices, SP caused brisk firing that was sustained after washout (Fig. 7, A to C). As observed with endocytic inhibitors, Span-Chol did not suppress the initial excitation but prevented sustained excitation. The SP-induced firing rate (normalized to $2 \mathrm{~min}$, events per 2 min) was $196.6 \pm 81.6$ for Span-Chol and 242.6 \pm 95.9 for Span $(P<0.05$, ANOVA, Sidak's test).

To evaluate whether endosomal targeting improves the efficacy and duration of action of $\mathrm{NK}_{1} \mathrm{R}$ antagonists for the treatment of pain, we administered cholestanol-conjugated or conventional antagonists by intrathecal injection 3 hours before intraplantar injection of capsaicin. This time was selected to allow endosomal accumulation of lipidated antagonists. When Cy5-Chol was injected intrathecally, probe was detected in laminae I to III neurons after 6 hours, confirming delivery and retention in pain-transmitting neurons (Fig. 7D). Cy5Chol did not affect nociception, which excludes nonspecific actions of cholestanol (Fig. 7E). Span-Chol, but not Span or SR140,333, inhibited capsaicin-evoked mechanical allodynia (Fig. 7E). When administered 30 min after capsaicin, intrathecal Span was transiently antinociceptive, whereas Span-Chol caused a delayed (3 hours), persistent (6 hours), and substantial ( $>50 \%$ ) antinociception (Fig. 7F).

The small-molecule $\mathrm{NK}_{1} \mathrm{R}$ antagonist L-733,060 (33) conjugated to Chol antagonized SP (3 $\mathrm{nM} ; \mathrm{EC}_{80}$ )-stimulated $\mathrm{Ca}^{2+}$ signaling in $\mathrm{HEK}-\mathrm{NK}_{1} \mathrm{R}$ cells [\% inhibition against $1 \mathrm{nM} \mathrm{SP}$ : $40.8 \pm 8.9(10 \mathrm{nM} \mathrm{L}-733,060)$ and $71.1 \pm 9.2(10 \mathrm{nM} \mathrm{L}-733,060-\mathrm{Chol})]$ and thus retained activity. When injected intrathecally 3 hours before intraplantar capsaicin, L-733,060-Chol was antinociceptive from 1 to 4 hours, whereas L-733,060 was antinociceptive only at 1 hour (Fig. 7G). 
When injected intrathecally 3 hours before intraplantar formalin, Span-Chol inhibited both phases of nocifensive behavior more completely than Span or SR140,333 (Fig. 7H). When injected intrathecally 36 hours after intraplantar CFA, Span-Chol inhibited mechanical hyperalgesia from 1 to 6 hours, whereas the antinociceptive actions of Span and SR140,333 were minor and transient for Span (Fig. 7, I and J).

The enhanced potency and duration of action of lipidated antagonists could be due to improved metabolic stability rather than to appropriate targeting of endosomal $\mathrm{NK}_{1} \mathrm{R}$. Membrane peptidases rapidly degrade neuropeptides, including SP, and could also degrade peptidic antagonists (5). Membranes prepared from mouse spinal cord rapidly degraded SP, but not Span or Span-Chol (Fig. 7K). Span and Span-Chol were also stable in human cerebrospinal fluid (Fig. 7L). These results suggest that enhanced stability does not account for the sustained antinociceptive actions of cholestanol-conjugated antagonists.

\section{DISCUSSION}

Our results support a reinterpretation of the notion that the primary physiological actions of GPCRs in vivo are mediated by cell surface receptors. By studying the $\mathrm{NK}_{1} \mathrm{R}$ as a prototypical GPCR that traffics to endosomes, we show that endosomal receptors convey sustained signals that underlie excitation and nociceptive transmission in spinal neurons and that targeting these receptors in endosomes is required for optimal pharmacological intervention.

We report that endosomal GPCRs generate a spectrum of signals in subcellular compartments. Clathrin and dynamin disruption prevented $\mathrm{NK}_{1} \mathrm{R}$ endocytosis and inhibited activation of nuclear ERK, cytosolic PKC, and cytosolic cAMP. Dynamin inhibitors also blocked SP-induced transcription, which is likely mediated by nuclear ERK. A C-terminally truncated mutant, $\mathrm{NK}_{1} \mathrm{R} \delta 311$, was also unable to internalize, activate nuclear ERK, or stimulate transcription. $\mathrm{Ga}_{\mathrm{q}}$ inhibition blocked $\mathrm{NK}_{1} \mathrm{R}$ endosomal signals, and endosomes contained both activated $\mathrm{NK}_{1} \mathrm{R}$ and $\mathrm{Ga}_{\mathrm{q}}$. Our results are consistent with the hypothesis that the $\mathrm{NK}_{1} \mathrm{R}$ in endosomes signals by $\mathrm{Ga}_{\mathrm{q}}$-dependent processes that activate nuclear ERK, cytosolic PKC, and cytosolic cAMP to cause nociception (Fig. 8A and movie S14). By delivering activated $\mathrm{NK}_{1} \mathrm{R}$ to endosomes and serving as a scaffold for signaling complexes, $\beta$ ARRs facilitate these signals $(9,22,23)$. Our findings add to the growing number of GPCRs, including $\beta_{2}$-adrenergic and thyroid-stimulating hormone receptors $(11,12)$, known to signal from endosomes by $\mathrm{G}$ protein-dependent processes, and provide in vivo evidence that this endosomal mechanism is physiologically relevant.

Together, our findings suggest that endosomal $\mathrm{NK}_{1} \mathrm{R}$ signaling is necessary for sustained excitation of spinal neurons and nociceptive transmission in the spinal cord, reveal a vital link between endosomal signaling and nociception, and provide information about the contribution of clathrin and dynamin to SP-induced excitation of spinal neurons and nociceptive transmission (Fig. 8B). The observations that dynamin and clathrin inhibitors attenuate $\mathrm{NK}_{1} \mathrm{R}$ endocytosis in spinal neurons and suppress neuronal excitation and nociception are consistent with a role for $\mathrm{NK}_{1} \mathrm{R}$ endocytosis in pain. The finding that selective disruption of $\mathrm{NK}_{1} \mathrm{R}-\beta \mathrm{ARR}$ interactions using membrane-permeant peptides and 
specific antagonism of endosomal $\mathrm{NK}_{1} \mathrm{R}$ with lipidated antagonists effectively suppress neuronal excitation and nociception in several models provides direct support for a major contribution of the endosomal $\mathrm{NK}_{1} \mathrm{R}$ to pain.

The discovery that endosomes are platforms for compartmentalized GPCR signaling that underlies pathophysiologically important processes in vivo has therapeutic implications. Delivery of antagonists to endosomes might facilitate the disruption of sustained signals from endosomal GPCRs that underlie disease and could provide enhanced efficacy and selectivity for treating pain (Fig. 8C). The accumulation of tripartite probes in $\mathrm{NK}_{1} \mathrm{R}$ positive endosomes demonstrates the feasibility of endosomal delivery. The capacity of Span-Chol and L-733,060-Chol, but not unconjugated antagonists, to specifically antagonize endosomal $\mathrm{NK}_{1} \mathrm{R}$ signaling and sustained excitation of spinal neurons and to cause prolonged and more effective antinociception demonstrates the importance of endosomal signaling for pain and illustrates the therapeutic utility of endosomally directed drugs.

Limitations of the use of pharmacological inhibitors of endocytosis include the widespread roles of dynamin and clathrin in vesicular transport and synaptic transmission $(34,35)$ and possible off-target actions of dynamin inhibitors (36). Thus, the actions of clathrin and dynamin inhibitors on excitation of spinal neurons and on nociceptive behavior might be unrelated to impaired $\mathrm{NK}_{1} \mathrm{R}$ signaling in endosomes and instead due to disrupted endocytosis or exocytosis of other GPCRs, ion channels, and transmitters that control pain transmission, or an artifact of abnormal motor function. However, clathrin and dynamin inhibitors did not affect fast synaptic transmission in the spinal cord or capsaicin-evoked neuropeptide release from spinal terminals of nociceptors and had no effect on motor coordination in vivo. These results suggest that synaptic transmission and vesicular transport were unaffected. The finding that dynamin 1 knockdown in the spinal cord also inhibited nociception suggests that off-target actions of dynamin inhibitors do not account for their antinociceptive properties. The observation that inhibitors of $\mathrm{NK}_{1} \mathrm{R}-\beta \mathrm{ARR}$ interactions and lipidated $\mathrm{NK}_{1} \mathrm{R}$ antagonists replicate the antinociceptive effects of endocytosis inhibitors supports a role for $\mathrm{NK}_{1} \mathrm{R}$ signaling in endosomes for nociception. Additional studies will be required to assess the selectivity of peptide inhibitors of $\mathrm{NK}_{1} \mathrm{R}-\beta A R R$ interactions. The antinociceptive actions of lipidated $\mathrm{NK}_{1} \mathrm{R}$ antagonists are unlikely to be related to enhanced stability, given the similar rate of metabolism of unconjugated and cholestanol-conjugated spantide, although detailed pharmacokinetic studies will be required to define the tissue distribution and degradation of lipidated $\mathrm{NK}_{1} \mathrm{R}$ antagonists in vivo. Evaluation of the therapeutic value of cholestanol-conjugated $\mathrm{NK}_{1} \mathrm{R}$ antagonists will require investigation of their potency and efficacy in disease-relevant models of pain.

$\mathrm{NK}_{1} \mathrm{R}$ redistributes from the plasma membrane to endosomes in chronic inflammatory and neurological diseases that are associated with persistent SP release (5). We propose that the inability of conventional antagonists to effectively target the $\mathrm{NK}_{1} \mathrm{R}$ in endosomes, where the receptor assembles a multiprotein signalosome in an acidic environment, contributes to their lack of clinical success (5). Our study suggests that therapeutic targeting of endosomal GPCRs is a paradigm of drug delivery that offers more effective and selective treatments for pathophysiological conditions, including chronic pain. 


\section{MATERIALS AND METHODS}

See the Supplementary Materials for full details of Materials and Methods.

\section{Study design}

The study was designed to examine the contribution of SP-induced endocytosis of the $\mathrm{NK}_{1} \mathrm{R}$ to signal transduction in subcellular compartments, excitation of spinal neurons, and nociception. Endocytosis of the $\mathrm{NK}_{1} \mathrm{R}$ was examined in HEK293 cells by using BRET to assess the proximity between the $\mathrm{NK}_{1} \mathrm{R}$ and proteins resident in the plasma membrane and early endosomes and by localizing fluorescent SP by confocal microscopy. BRET was also used to examine the assembly of signaling complexes, which were localized in endosomes by immunofluorescence and super-resolution microscopy. Signaling in subcellular compartments of HEK293 cells was studied by expressing genetically encoded FRET biosensors, which allowed analysis of signaling with high spatial and temporal fidelity. $\mathrm{NK}_{1} \mathrm{R}$ endocytosis was studied in spinal neurons in slice preparations and in vivo by immunofluorescence and confocal microscopy. To examine the excitation of paintransmitting neurons, cell-attached patch clamp recordings were made from second-order neurons in slices of rat spinal cord. Nociceptive behavior was evaluated in conscious mice after intraplantar administration of capsaicin, formalin, or CFA. To examine the contribution of $\mathrm{NK}_{1} \mathrm{R}$ endocytosis to signaling, neuronal excitation, and nociception, HEK293 cells, rat spinal cord slices, or mice were treated with pharmacological or genetic inhibitors of clathrin, dynamin, or $\beta A R R s$, or with peptide inhibitors of $\mathrm{NK}_{1} \mathrm{R} / \beta \mathrm{ARR}$ interactions. Peptidic and small-molecule antagonists of the $\mathrm{NK}_{1} \mathrm{R}$ were conjugated to the lipid cholestanol, which facilitated endosomal targeting and retention of antagonists. Cholestanolconjugated antagonists were used to directly evaluate the contribution of $\mathrm{NK}_{1} \mathrm{R}$ signaling in endosomes to SP-induced compartmentalized signaling in HEK293 cells, excitation of spinal neurons, and nociception. Institutional Animal Care and Use Committees approved all studies.

\section{Statistical analyses}

Data are presented as means \pm SEM, unless noted otherwise. Differences were assessed using Student's $t$ test for two comparisons. For multiple comparisons, differences were assessed using one- or two-way ANOVA followed by Dunnett's multiple comparison test, Tukey's multiple comparison test, Sidak's multiple comparisons test, or Dunn's multiple comparisons test. Table S1 provides full details of statistical tests and replicates for each experiment.

\section{Supplementary Material}

Refer to Web version on PubMed Central for supplementary material.

\section{Acknowledgments}

We thank C. Nowell for image analysis and F. Chiu for analysis of probe degradation.

Funding: This work was supported by National Health and Medical Research Council (NHMRC) grants 63303, 1049682, and 1031886; the Australia Research Council Centre of Excellence in Convergent Bio-Nano Science and 
Technology; and Monash University (to N.W.B.); by NHMRC grants 1047070, 1032771, 1022218, 1017063, and 1011457; the Australian Cancer Research Foundation; and the Ramaciotti Foundation (to P.J.R. and A.M.); and by Takeda Pharmaceuticals Inc. M.L.H. is an NHMRC R.D. Wright Career Development Fellow (1061687) and M.C. is a Monash Fellow.

\section{REFERENCES AND NOTES}

1. Basbaum AI, Bautista DM, Scherrer G, Julius D. Cellular and molecular mechanisms of pain. Cell. 2009; 139:267-284. [PubMed: 19837031]

2. Han B, Compton WM, Jones CM, Cai R. Nonmedical prescription opioid use and use disorders among adults aged 18 through 64 years in the United States, 2003-2013. JAMA. 2015; 314:14681478. [PubMed: 26461997]

3. Audet M, Bouvier M. Insights into signaling from the $\beta_{2}$-adrenergic receptor structure. Nat Chem Biol. 2008; 4:397-403. [PubMed: 18560432]

4. Geppetti P, Veldhuis NA, Lieu T, Bunnett NW. G protein-coupled receptors: Dynamic machines for signaling pain and itch. Neuron. 2015; 88:635-649. [PubMed: 26590341]

5. Steinhoff MS, von Mentzer B, Geppetti P, Pothoulakis C, Bunnett NW. Tachykinins and their receptors: Contributions to physiological control and the mechanisms of disease. Phys Rev. 2014; 94:265-301.

6. DeWire SM, Ahn S, Lefkowitz RJ, Shenoy SK. $\beta$-Arrestins and cell signaling. Annu Rev Physiol. 2007; 69:483-510. [PubMed: 17305471]

7. Irannejad R, von Zastrow M. GPCR signaling along the endocytic pathway. Curr Opin Cell Biol. 2014; 27:109-116. [PubMed: 24680436]

8. Murphy JE, Padilla BE, Hasdemir B, Cottrell GS, Bunnett NW. Endosomes: A legitimate platform for the signaling train. Proc Natl Acad Sci USA. 2009; 106:17615-17622. [PubMed: 19822761]

9. DeFea KA, Vaughn ZD, O'Bryan EM, Nishijima D, Déry O, Bunnett NW. The proliferative and antiapoptotic effects of substance $P$ are facilitated by formation of a $\beta$-arrestin-dependent scaffolding complex. Proc Natl Acad Sci USA. 2000; 97:11086-11091. [PubMed: 10995467]

10. DeFea KA, Zalevsky J, Thoma MS, Déry O, Mullins RD, Bunnett NW. $\beta$-Arrestin-dependent endocytosis of proteinase-activated receptor 2 is required for intracellular targeting of activated ERK1/2. J Cell Biol. 2000; 148:1267-1281. [PubMed: 10725339]

11. Calebiro D, Nikolaev VO, Gagliani MC, de Filippis T, Dees C, Tacchetti C, Persani L, Lohse MJ. Persistent cAMP-signals triggered by internalized G-protein-coupled receptors. PLOS Biol. 2009; 7:e1000172. [PubMed: 19688034]

12. Irannejad R, Tomshine JC, Tomshine JR, Chevalier M, Mahoney JP, Steyaert J, Rasmussen SGF, Sunahara RK, El-Samad H, Huang B, von Zastrow M. Conformational biosensors reveal GPCR signalling from endosomes. Nature. 2013; 495:534-538. [PubMed: 23515162]

13. Thomsen ARB, Plouffe B, Cahill TJ III, Shukla AK, Tarrasch JT, Dosey AM, Kahsai AW, Strachan RT, Pani B, Mahoney JP, Huang L, Breton B, Heydenreich FM, Sunahara RK, Skiniotis G, Bouvier M, Lefkowitz RJ. GPCR-G protein- $\beta$-arrestin super-complex mediates sustained G protein signaling. Cell. 2016; 166:907-919. [PubMed: 27499021]

14. Mantyh PW, DeMaster E, Malhotra A, Ghilardi JR, Rogers SD, Mantyh CR, Liu H, Basbaum AI, Vigna SR, Maggio JE, Simone DA. Receptor endocytosis and dendrite reshaping in spinal neurons after somatosensory stimulation. Science. 1995; 268:1629-1632. [PubMed: 7539937]

15. Jarcho JM, Feier NA, Bert A, Labus JA, Lee M, Stains J, Ebrat B, Groman SM, Tillisch K, Brody AL, London ED, Mandelkern MA, Mayer EA. Diminished neurokinin-1 receptor availability in patients with two forms of chronic visceral pain. Pain. 2013; 154:987-996. [PubMed: 23582152]

16. McConalogue K, Déry O, Lovett M, Wong H, Walsh JH, Grady EF, Bunnett NW. Substance Pinduced trafficking of $\beta$-arrestins. The role of $\beta$-arrestins in endocytosis of the neurokinin- 1 receptor. J Biol Chem. 1999; 274:16257-16268. [PubMed: 10347182]

17. Robertson MJ, Deane FM, Robinson PJ, McCluskey A. Synthesis of Dynole 34-2, Dynole 2-24 and Dyngo 4a for investigating dynamin GTPase. Nat Protoc. 2014; 9:851-870. [PubMed: 24651498] 
18. Robertson MJ, Deane FM, Stahlschmidt W, von Kleist L, Haucke V, Robinson PJ, McCluskey A. Synthesis of the Pitstop family of clathrin inhibitors. Nat Protoc. 2014; 9:1592-1606. [PubMed: 24922269]

19. Schmidlin F, Déry O, DeFea KO, Slice L, Patierno S, Sternini C, Grady EF, Bunnett NW. Dynamin and Rab5a-dependent trafficking and signaling of the neurokinin 1 receptor. J Biol Chem. 2001; 276:25427-25437. [PubMed: 11306580]

20. Halls ML, Poole DP, Ellisdon AM, Nowell CJ, Canals M. Detection and quantification of intracellular signaling using FRET-based biosensors and high content imaging. Methods Mol Biol. 2015; 1335:131-161. [PubMed: 26260599]

21. Tsvetanova NG, Irannejad R, von Zastrow M. G protein-coupled receptor (GPCR) signaling via heterotrimeric G proteins from endosomes. J Biol Chem. 2015; 290:6689-6696. [PubMed: 25605726]

22. Cottrell GS, Padilla BE, Amadesi S, Poole DP, Murphy JE, Hardt M, Roosterman D, Steinhoff M, Bunnett NW. Endosomal endothelin-converting enzyme-1: A regulator of $\beta$-arrestin-dependent ERK signaling. J Biol Chem. 2009; 284:22411-22425. [PubMed: 19531493]

23. Jensen DD, Halls ML, Murphy JE, Canals M, Cattaruzza F, Poole DP, Lieu T, Koon HW, Pothoulakis C, Bunnett NW. Endothelin-converting enzyme 1 and $\beta$-arrestins exert spatiotemporal control of substance P-induced inflammatory signals. J Biol Chem. 2014; 289:20283-20294. [PubMed: 24898255]

24. Davies SP, Reddy H, Caivano M, Cohen P. Specificity and mechanism of action of some commonly used protein kinase inhibitors. Biochem J. 2000; 351:95-105. [PubMed: 10998351]

25. Ji RR, Befort K, Brenner GJ, Woolf CJ. ERK MAP kinase activation in superficial spinal cord neurons induces prodynorphin and NK-1 upregulation and contributes to persistent inflammatory pain hypersensitivity. J Neurosci. 2002; 22:478-485. [PubMed: 11784793]

26. Murase K, Randić M. Actions of substance P on rat spinal dorsal horn neurones. J Physiol. 1984; 346:203-217. [PubMed: 6199493]

27. Emonds-Alt X, Doutremepuich JD, Heaulme M, Neliat G, Santucci V, Steinberg R, Vilain P, Bichon D, Ducoux JP, Proietto V, Van Broeck D, Soubrié P, Le Fu G, Breliére JC. In vitro and in vivo biological activities of SR140333, a novel potent non-peptide tachykinin $\mathrm{NK}_{1}$ receptor antagonist. Eur J Pharmacol. 1993; 250:403-413. [PubMed: 7509286]

28. Roosterman D, Cottrell GS, Schmidlin F, Steinhoff M, Bunnett NW. Recycling and resensitization of the neurokinin 1 receptor. Influence of agonist concentration and Rab GTPases. J Biol Chem. 2004; 279:30670-30679. [PubMed: 15128739]

29. Roosterman D, Cottrell GS, Padilla BE, Muller L, Eckman CB, Bunnett NW, Steinhoff M. Endothelin-converting enzyme 1 degrades neuropeptides in endosomes to control receptor recycling. Proc Natl Acad Sci USA. 2007; 104:11838-11843. [PubMed: 17592116]

30. Sato PY, Chuprun JK, Schwartz M, Koch WJ. The evolving impact of G protein-coupled receptor kinases in cardiac health and disease. Phys Rev. 2015; 95:377-404.

31. Rajendran L, Udayar V, Goodger ZV. Lipid-anchored drugs for delivery into subcellular compartments. Trends Pharmacol Sci. 2012; 33:215-222. [PubMed: 22385603]

32. Folkers K, Håkanson R, Hörig J, Xu JC, Leander S. Biological evaluation of substance P antagonists. Br J Pharmacol. 1984; 83:449-456. [PubMed: 6207886]

33. Rupniak NM, Carlson E, Boyce S, Webb JK, Hill RG. Enantioselective inhibition of the formalin paw late phase by the NK1 receptor antagonist L-733,060 in gerbils. Pain. 1996; 67:189-195. [PubMed: 8895247]

34. Heymann JA, Hinshaw JE. Dynamins at a glance. J Cell Sci. 2009; 122:3427-3431. [PubMed: 19759282]

35. McMahon HT, Boucrot E. Molecular mechanism and physiological functions of clathrin-mediated endocytosis. Nat Rev Mol Cell Biol. 2011; 12:517-533. [PubMed: 21779028]

36. Park RJ, Shen H, Liu L, Liu X, Ferguson SM, De Camilli P. Dynamin triple knockout cells reveal off target effects of commonly used dynamin inhibitors. J Cell Sci. 2013; 126:5305-5312. [PubMed: 24046449] 
37. Kocan M, Dalrymple MB, Seeber RM, Feldman BJ, Pfleger KDG. Enhanced BRET technology for the monitoring of agonist-induced and agonist-independent interactions between GPCRs and $\beta$ arrestins. Front Endocrinol. 2010; 1:12.

38. Lan TH, Liu Q, Li C, Wu G, Lambert NA. Sensitive and high resolution localization and tracking of membrane proteins in live cells with BRET. Traffic. 2012; 13:1450-1456. [PubMed: 22816793]

39. Harvey CD, Ehrhardt AG, Cellurale C, Zhong H, Yasuda R, Davis RJ, Svoboda K. A genetically encoded fluorescent sensor of ERK activity. Proc Natl Acad Sci USA. 2008; 105:19264-19269. [PubMed: 19033456]

40. Violin JD, Zhang J, Tsien RY, Newton AC. A genetically encoded fluorescent reporter reveals oscillatory phosphorylation by protein kinase C. J Cell Biol. 2003; 161:899-909. [PubMed: 12782683]

41. Nikolaev VO, Bünemann M, Hein L, Hannawacker A, Lohse MJ. Novel single chain cAMP sensors for receptor-induced signal propagation. J Biol Chem. 2004; 279:37215-37218. [PubMed: 15231839]

42. Wachten S, Masada N, Ayling LJ, Ciruela A, Nikolaev VO, Lohse MJ, Cooper DM. Distinct pools of cAMP centre on different isoforms of adenylyl cyclase in pituitary-derived GH3B6 cells. J Cell Sci. 2010; 123:95-106. [PubMed: 20016070]

43. Déry O, Defea KA, Bunnett NW. Protein kinase C-mediated desensitization of the neurokinin 1 receptor. Am J Physiol Cell Physiol. 2001; 280:C1097-C1106. [PubMed: 11287322]

44. Halls ML, Bathgate RAD, Summers RJ. Comparison of signaling pathways activated by the relaxin family peptide receptors, RXFP1 and RXFP2, using reporter genes. J Pharmacol Exp Ther. 2007; 320:281-290. [PubMed: 17065365]

45. Yu XH, Ribeiro-da-Silva A, De Koninck Y. Morphology and neurokinin 1 receptor expression of spinothalamic lamina I neurons in the rat spinal cord. J Comp Neurol. 2005; 491:56-68. [PubMed: 16127696]

46. Imlach WL, Bhola RF, May LT, Christopoulos A, Christie MJ. A positive allosteric modulator of the adenosine $A_{1}$ receptor selectively inhibits primary afferent synaptic transmission in a neuropathic pain model. Mol Pharm. 2015; 88:460-468.

47. Amadesi S, Nie J, Vergnolle N, Cottrell GS, Grady EF, Trevisani M, Manni C, Geppetti P, McRoberts JA, Ennes H, Davis JB, Mayer EA, Bunnett NW. Protease-activated receptor 2 sensitizes the capsaicin receptor transient receptor potential vanilloid receptor 1 to induce hyperalgesia. J Neurosci. 2004; 24:4300-4312. [PubMed: 15128844]

48. Grady EF, Baluk P, Böhm S, Gamp PD, Wong H, Payan DG, Ansel J, Portbury AL, Furness JB, McDonald DM, Bunnett NW. Characterization of antisera specific to NK1, NK2, and NK3 neurokinin receptors and their utilization to localize receptors in the rat gastrointestinal tract. $\mathrm{J}$ Neurosci. 1996; 16:6975-6986. [PubMed: 8824334]

49. Alemi F, Kwon E, Poole DP, Lieu T, Lyo V, Cattaruzza F, Cevikbas F, Steinhoff M, Nassini R, Materazzi S, Guerrero-Alba R, Valdez-Morales E, Cottrell GS, Schoonjans K, Geppetti P, Vanner SJ, Bunnett NW, Corvera CU. The TGR5 receptor mediates bile acid-induced itch and analgesia. J Clin Invest. 2013; 123:1513-1530. [PubMed: 23524965]

50. Poole DP, Amadesi S, Veldhuis NA, Abogadie FC, Lieu T, Darby W, Liedtke W, Lew MJ, McIntyre P, Bunnett NW. Protease-activated receptor $2\left(\mathrm{PAR}_{2}\right)$ protein and transient receptor potential vanilloid 4 (TRPV4) protein coupling is required for sustained inflammatory signaling. $\mathrm{J}$ Biol Chem. 2013; 288:5790-5802. [PubMed: 23288842]

51. Schlegel A, Largeau C, Bigey P, Bessodes M, Lebozec K, Scherman D, Escriou V. Anionic polymers for decreased toxicity and enhanced in vivo delivery of siRNA complexed with cationic liposomes. J Control Release. 2011; 152:393-401. [PubMed: 21497175]

52. Fa M, Staniszewski A, Saeed F, Francis YI, Arancio O. Dynamin 1 is required for memory formation. PLOS ONE. 2014; 9:e91954. [PubMed: 24643165]

53. Tan TC, Valova VA, Malladi CS, Graham ME, Berven LA, Jupp OJ, Hansra G, McClure SJ, Sarcevic B, Boadle RA, Larsen MR, Cousin MA, Robinson PJ. Cdk5 is essential for synaptic vesicle endocytosis. Nat Cell Biol. 2003; 5:701-710. [PubMed: 12855954] 
54. Bunnett NW, Kobayashi R, Orloff MS, Reeve JR, Turner AJ, Walsh JH. Catabolism of gastrin releasing peptide and substance $\mathrm{P}$ by gastric membrane-bound peptidases. Peptides. 1985; 6:277283. 

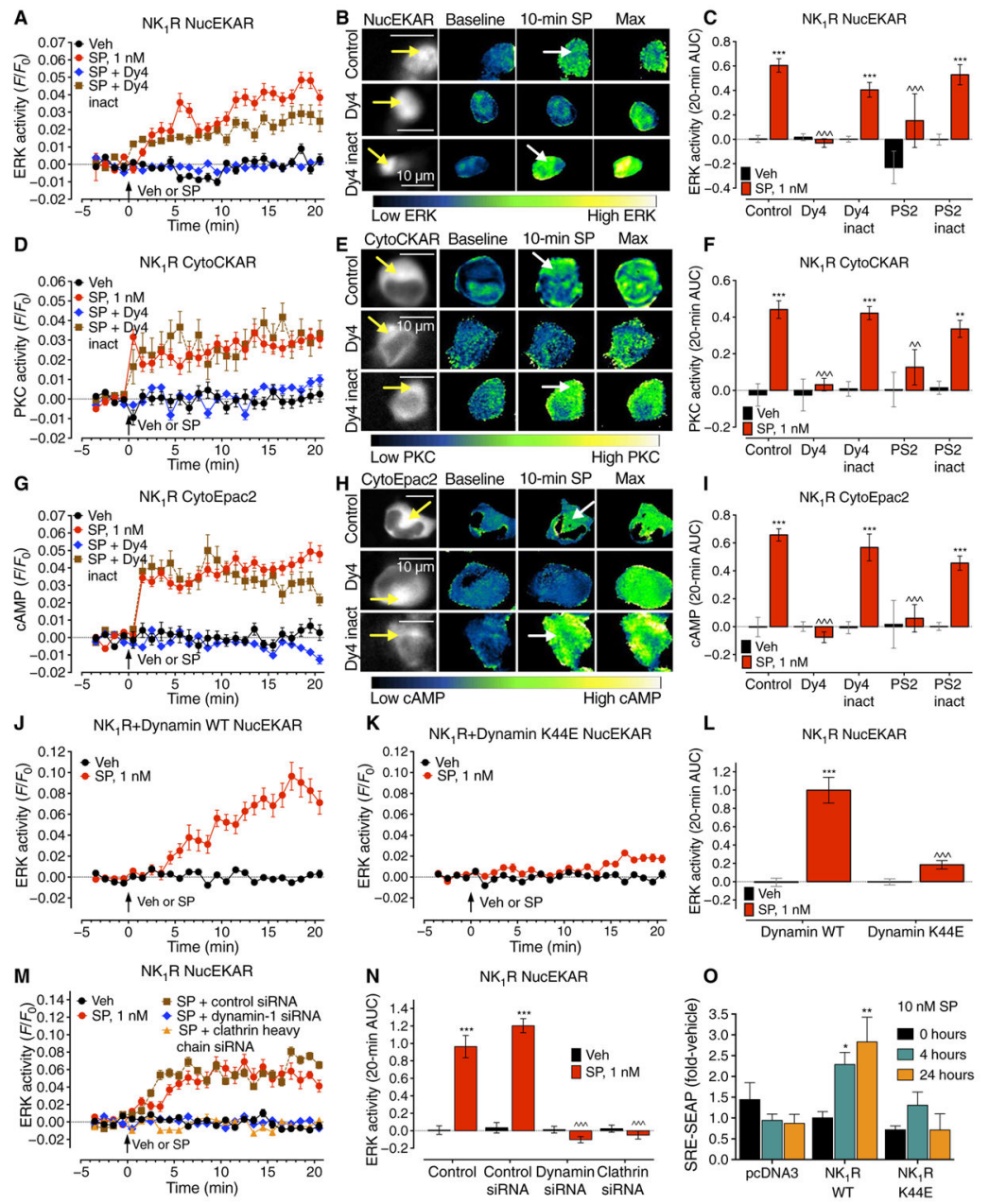

Fig. 1. $N_{1} R$ endocytosis-dependent compartmentalized signaling (A to I) Effect of inhibitors of dynamin (Dy4) and clathrin (PS2), and of inactive (inact) analogs, on SP-induced spatiotemporal signaling profiles for nuclear ERK (NucEKAR) (A to C), cytosolic PKC (CytoCKAR) (D to F), and cytosolic cAMP (CytoEpac2) (G to I) measured in HEK293 cells using FRET biosensors. (A, D, and G) Time course of responses. (B, E, and H). Representative ratiometric images and sensor localization. Max, response to positive controls. Yellow arrows denote localization of FRET sensor and white arrows show the SP-stimulated signals in control cells and cells treated with Dy4 inact. (C, F, and I) Area under the curve (AUC) of (A), (D), and (G). (J and $\mathbf{K}$ ) Effect of dynamin WT (J) or dominant negative K44E (K) overexpression on the spatiotemporal profile of SP-induced nuclear ERK. (L) AUC of (J) and (K). (M) Effect of clathrin heavy chain and dynamin-1 siRNA on the spatiotemporal profile of SP-induced nuclear ERK. (N) AUC of (M). (O) Effect of dynamin WT or K44E overexpression on the SP-induced SRE-SEAP. $* P<0.05$, $* * P<0.01,{ }^{* * *} P<0.001$, vehicle (Veh); ${ }^{\wedge} P P<0.01, \wedge \wedge \wedge P<0.001$, control to inhibitors. (A to N) Thirty to 354 cells, three to five experiments. (O) $n=3$ experiments. ANOVA, Tukey's test (C, F, I, and N); Sidak's test (L); Dunnett's test (O). 

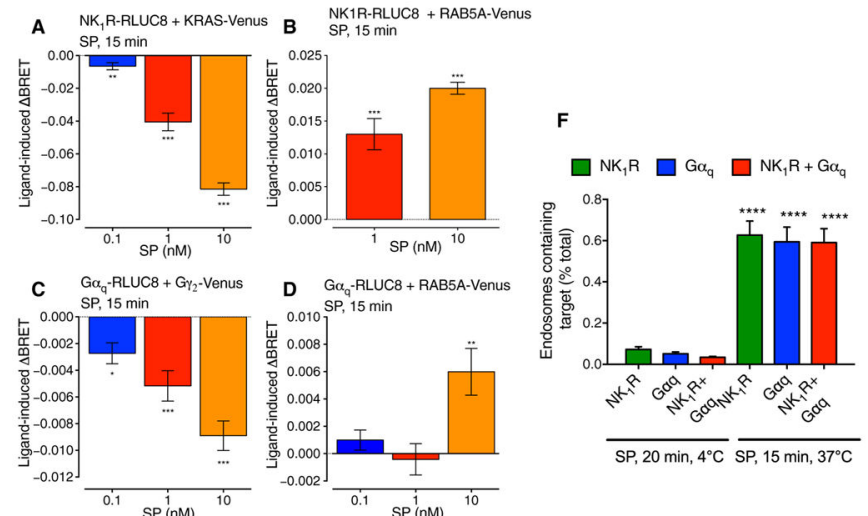

E $\quad \mathrm{NK}_{1} \mathrm{R}$, Alexa 488; G $\alpha_{\mathrm{q}}$, Alexa 568; EEA1, Alexa 647

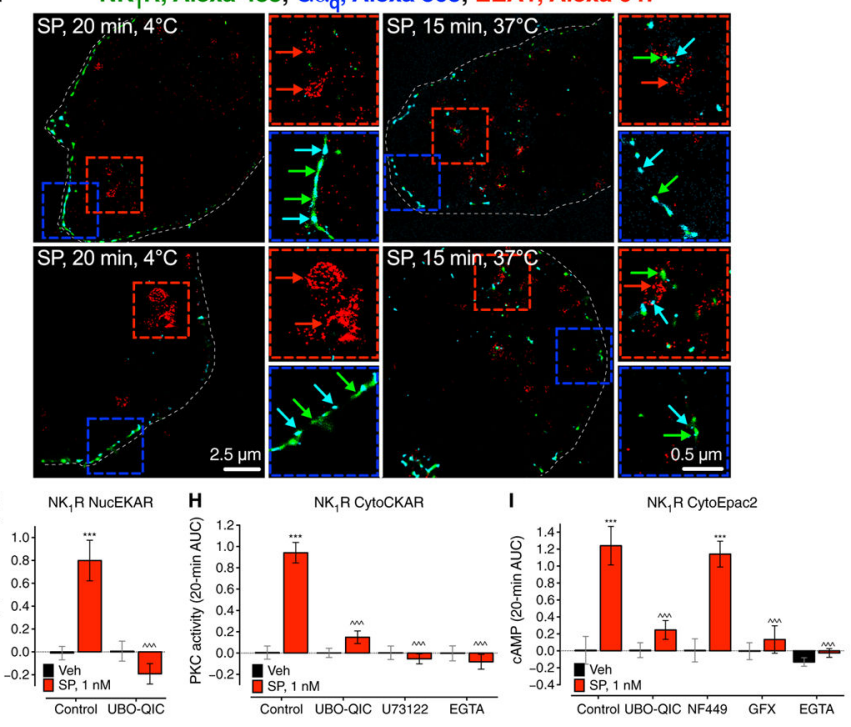

Fig. 2. G protein-dependent $\mathrm{NK}_{1} \mathrm{R}$ signaling in endosomes

(A to D) SP-induced BRET between $\mathrm{NK}_{1}$ R-RLUC8 and KRAS-Venus (A) or RAB5AVenus (B) and between $\mathrm{Ga}_{\mathrm{q}}$-RLUC8 and $\mathrm{G}_{2}$-Venus (C) or RAB5A-Venus (D) in HEK293 cells. $* P<0.05, * * P<0.01, * * * P<0.001$ to baseline. Triplicate observations, $n \geq 3$ experiments. (E) Localization of $\mathrm{NK}_{1} \mathrm{R}$-IR (green), $\mathrm{Ga}_{\mathrm{q}}$-IR (cyan), and EEA1-IR (red) in HEK293 cells by super-resolution microscopy. Blue boxes, plasma membrane; red boxes, endosomes. (F) Quantification of the proportion of endosomes containing $\mathrm{NK}_{1} \mathrm{R}-\mathrm{IR}$ and $\mathrm{Ga}_{\mathrm{q}}$-IR. Sixty to 66 cells per condition (20 to 22 cells from $n=3$ experiments). $* * * * P<$ 0.0001. ( $\mathbf{G}$ to I) Effect of inhibitors of $\mathrm{Ga}_{\mathrm{q}}$ (UBO-QIC) or PLC (U73122) and $\mathrm{Ca}^{2+}$ chelation (EGTA) or inhibitors of $\mathrm{Ga}_{\mathrm{S}}(\mathrm{NF} 449)$ or PKC (GF109203X, GFX) on SP-induced nuclear ERK (G), cytosolic PKC (H), and cytosolic cAMP (I) measured using FRET biosensors. $* * * P<0.001$, SP to vehicle; ${ }^{\wedge \wedge} \wedge P<0.001$, control to inhibitor. Thirty-five to 67 cells, three experiments. ANOVA, Dunnett's test (A to D); Sidak's test (F and G); Tukey's test (H and I). 


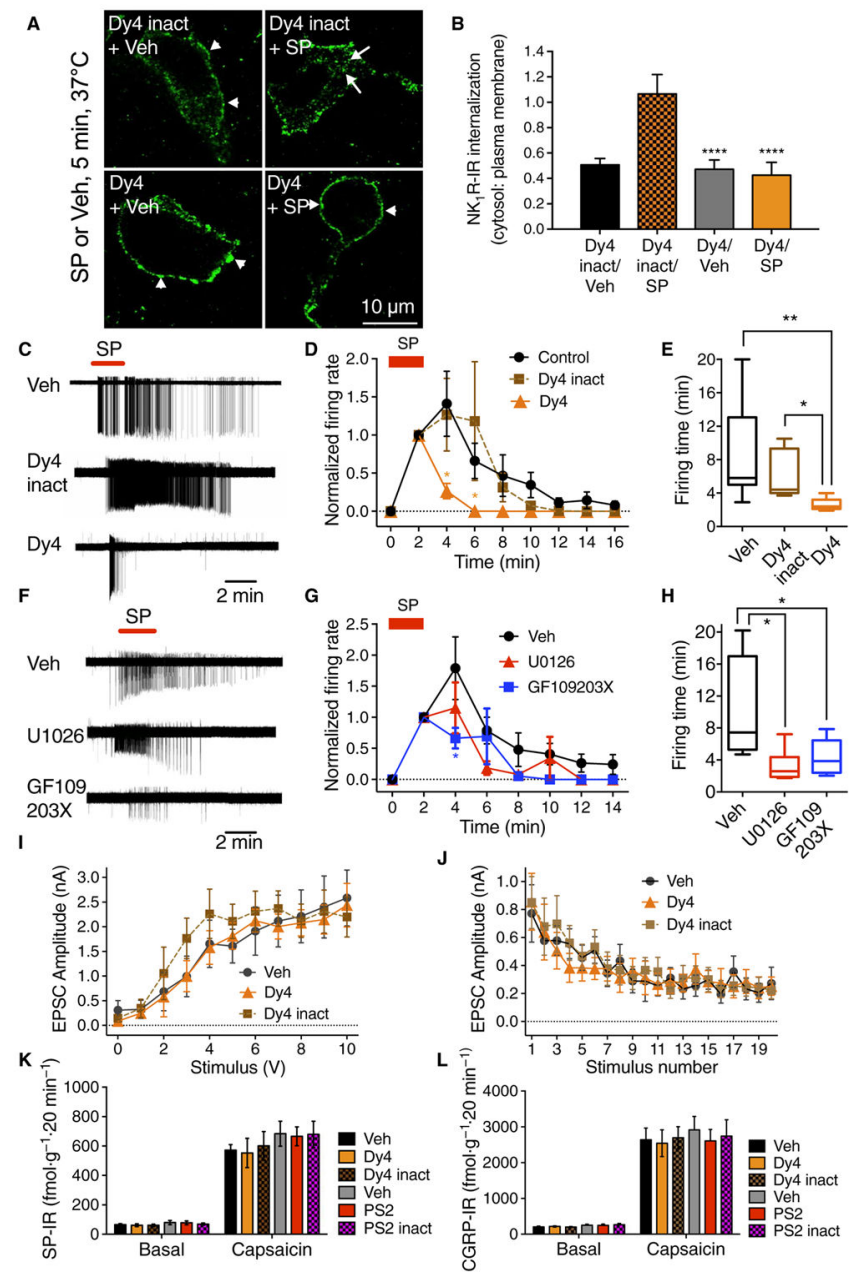

Fig. 3. $\mathrm{NK}_{1} \mathrm{R}$ endocytosis and neuronal excitation in spinal cord slices

(A) Effect of Dy4 and Dy4 inact on SP-induced endocytosis of $\mathrm{NK}_{1} \mathrm{R}$-IR in rat spinal neurons. Arrows, internalized; arrowheads, cell surface $\mathrm{NK}_{1} \mathrm{R}$. (B) Quantification of endocytosis. $* * * * P<0.0001$. Eighteen neurons per group (six neurons in slices from $n=3$ rats). (C to H) Effects of Dy4, Dy4 inact, U0126 (MEK inhibitor), and GF109203X (PKC inhibitor) on SP-induced firing of rat spinal neurons. (C and F) Representative traces. (D and $\mathrm{G})$ Firing rate normalized to $2 \mathrm{~min}$. $(\mathrm{E}$ and $\mathrm{H}$ ) Firing duration to last action potential. Six to 7 neurons per group from $n=8$ to 17 rats. $* P<0.05$, $* * P<0.01$. (I and $\mathbf{J}$ ) Effect of Dy4 and Dy4 inact on EPSC in lamina $\mathrm{I} / \mathrm{II}_{\mathrm{O}}$ induced by primary afferent stimulation, $n=11$ neurons. (K and $\mathbf{L}$ ) Effects of Dy4, PS2, and inactive analogs on capsaicin-stimulated SP-IR (K) and CGRP-IR (L) release from segments of mouse spinal cord. $n=6$ experiments. ANOVA, Tukey's test (B); Sidak's test (D and G); Dunn's test (E and H). 


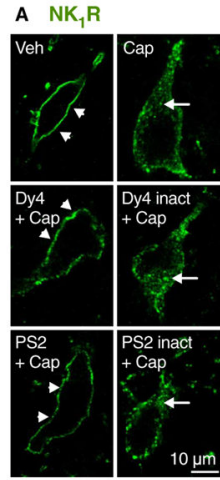

E

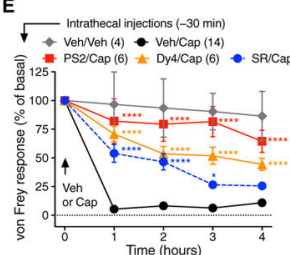

H

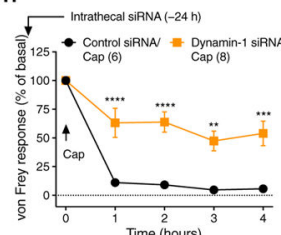

Intrathecal injections (-30 min)

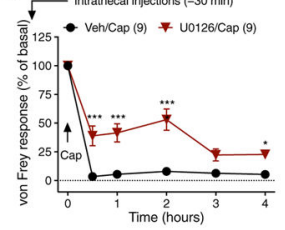

B pERK NeuN

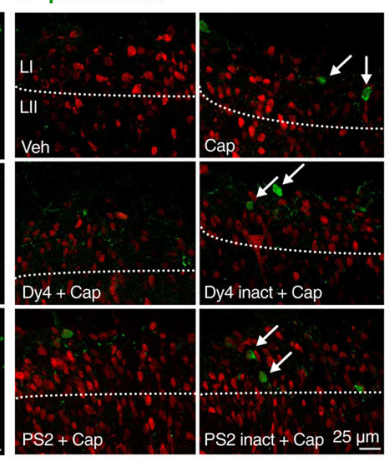

$F$
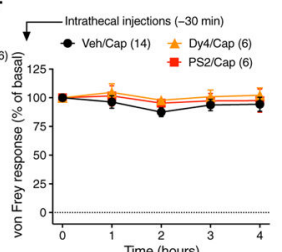

I
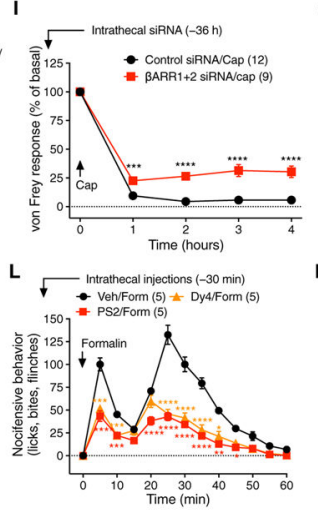

C

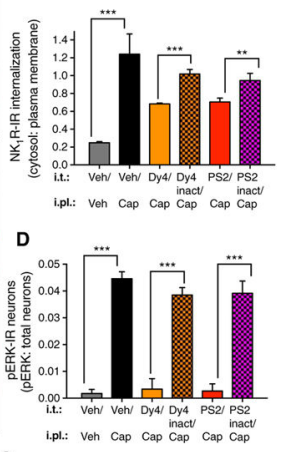

G

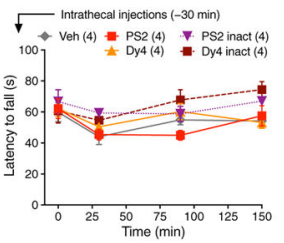

$\mathbf{J}$
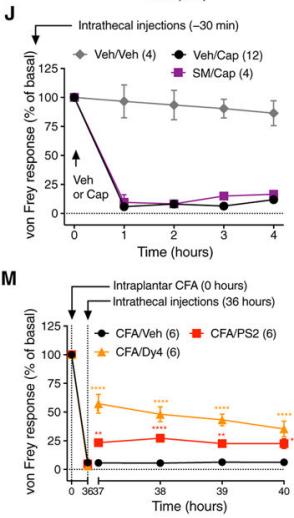

Fig. 4. $N_{1} R$ endocytosis, ERK signaling, and nociception in vivo Effects of intrathecal (i.t.) injections of inhibitors or siRNA. (A and $\mathbf{B}$ ) Localization of $\mathrm{NK}_{1} \mathrm{R}-\mathrm{IR}(\mathrm{A})$ and $\mathrm{pERK}-\mathrm{IR}(\mathrm{B})$ in rat spinal neurons $10 \mathrm{~min}$ after intraplantar (i.pl.) vehicle or capsaicin (Cap). L, lamina. (A) Arrowheads show cell surface and arrows show endosomal $\mathrm{NK}_{1}$ R. (B) Arrows show pERK-IR (green) and red shows NeuN (neuronal marker). (C and $\mathbf{D})$ Quantification of $\mathrm{NK}_{1} \mathrm{R}$ endocytosis (C) and pERK-expressing neurons (D). ${ }^{* *} P<0.01, * * * P<0.001$. Neuronal numbers: Veh, 54; capsaicin, 52; Dy4, 28; Dy 4 inact, 18; PS2, 22; PS2 inact, 19 ( $\square$ neurons in sections from $n=3$ rats). (E, $\mathbf{F}, \mathbf{H}$, to $\mathbf{K}$ ) Nociception in mice after intrathecal injection of endocytic inhibitors (Dy4, PS2), $\mathrm{NK}_{1} \mathrm{R}$ antagonist (SR140,333; SR), dynamin-1 siRNA, $\beta$ ARR1/2 siRNA, endothelin-converting enzyme-1 inhibitor (SM-19712; SM), or MEK inhibitor (U0126). von Frey withdrawal responses of capsaicin-injected (E and H to K) or contralateral (F) paw. (G) Rotarod latency. (L) Formalin (form) nocifensive behavior. (M) von Frey withdrawal responses of the CFAinjected paw. $* P<0.05,{ }^{*} P<0.01, * * * P<0.001, * * * * P<0.0001$, to control. Student's $t$ test (C and D); ANOVA, Dunnett's test (E to $\mathrm{M})$. 
A
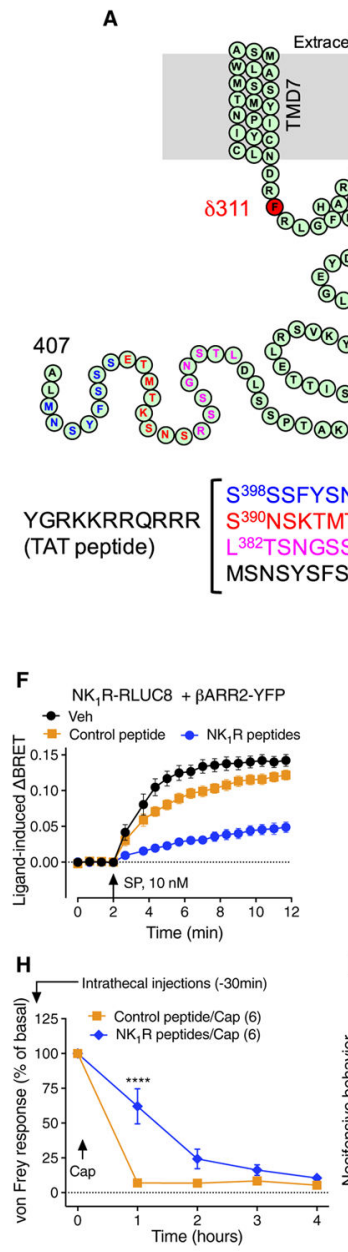
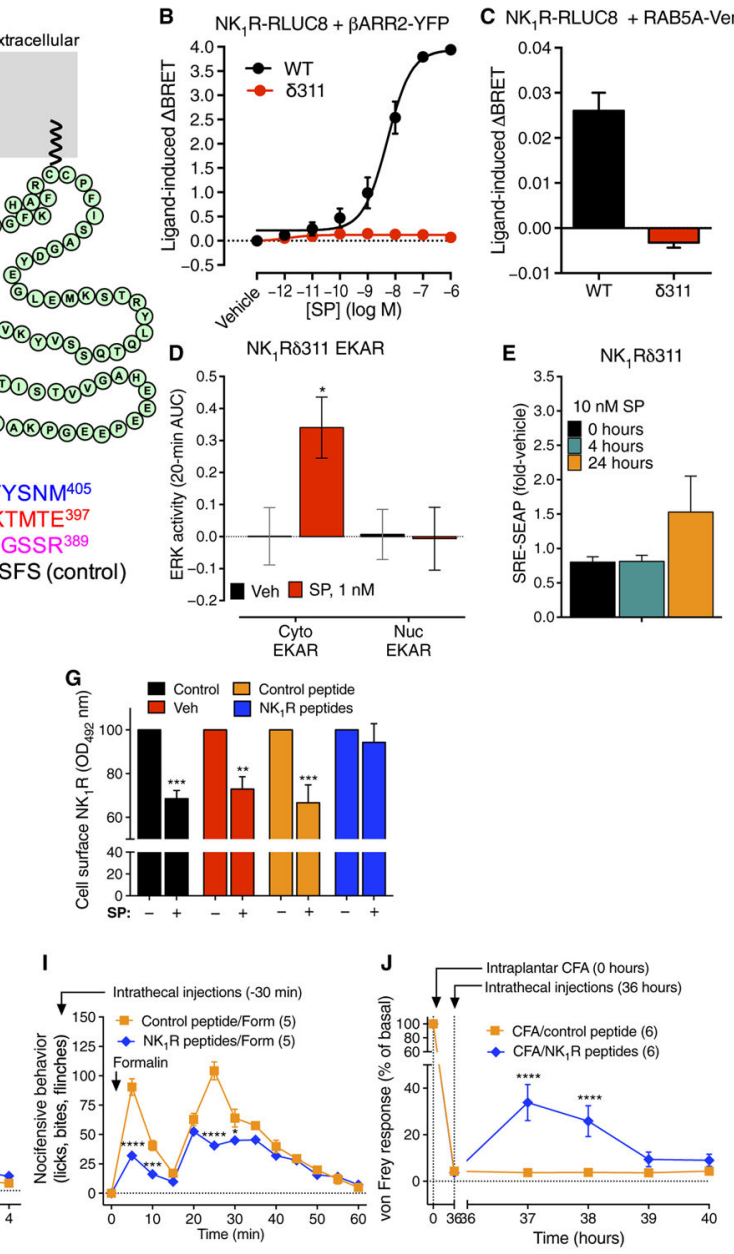

Fig. 5. Disruption of $N K_{1} R / \beta A R R$ interactions

(A) Mouse $\mathrm{NK}_{1} \mathrm{R} C$ terminus, indicating $\mathrm{NK}_{1} \mathrm{R} \delta 311$ truncation and sequences of Tatconjugated $\mathrm{NK}_{1} \mathrm{R}$ and control peptides. (B and $\mathbf{C}$ ) SP-induced BRET between WT NK $\mathrm{N}_{1} \mathrm{R}$ RLUC8 or $\mathrm{NK}_{1}$ R8311-RLUC8 and $\beta A R R 2-\mathrm{YFP}$ (B) or RAB5A-Venus (C). Triplicate observations, $n \geq 3$ experiments. (D) SP-induced cytosolic ERK (CytoEKAR) and nuclear ERK (NucEKAR) measured using FRET biosensors. $* P<0.05$. Forty-nine to 99 cells, three experiments. (E) Effect of SP on SRE-SEAP release from HEK-NK ${ }_{1}$ R $\delta 311$ cells. (F and $\left.\mathbf{G}\right)$ Effect of control and three $\mathrm{NK}_{1} \mathrm{R}$ peptides on SP-induced $\mathrm{NK}_{1} \mathrm{R}$-RLUC8/BARR2-YFP BRET (F) and $\mathrm{NK}_{1} \mathrm{R}$ endocytosis $(\mathrm{G})$. (H to $\left.\mathbf{J}\right)$ Effects of intrathecally administered control and $\mathrm{NK}_{1} \mathrm{R}$ peptides on capsaicin-induced mechanical allodynia $(\mathrm{H})$, formalin-evoked nocifensive behavior (I), and CFA-induced mechanical hyperalgesia (J) in mice. $* P<0.05$, $* * P<0.01, * * * P<0.001, * * * * P<0.0001$ to control. ANOVA, Sidak's test (D and G); Dunnett's test (H to J). 

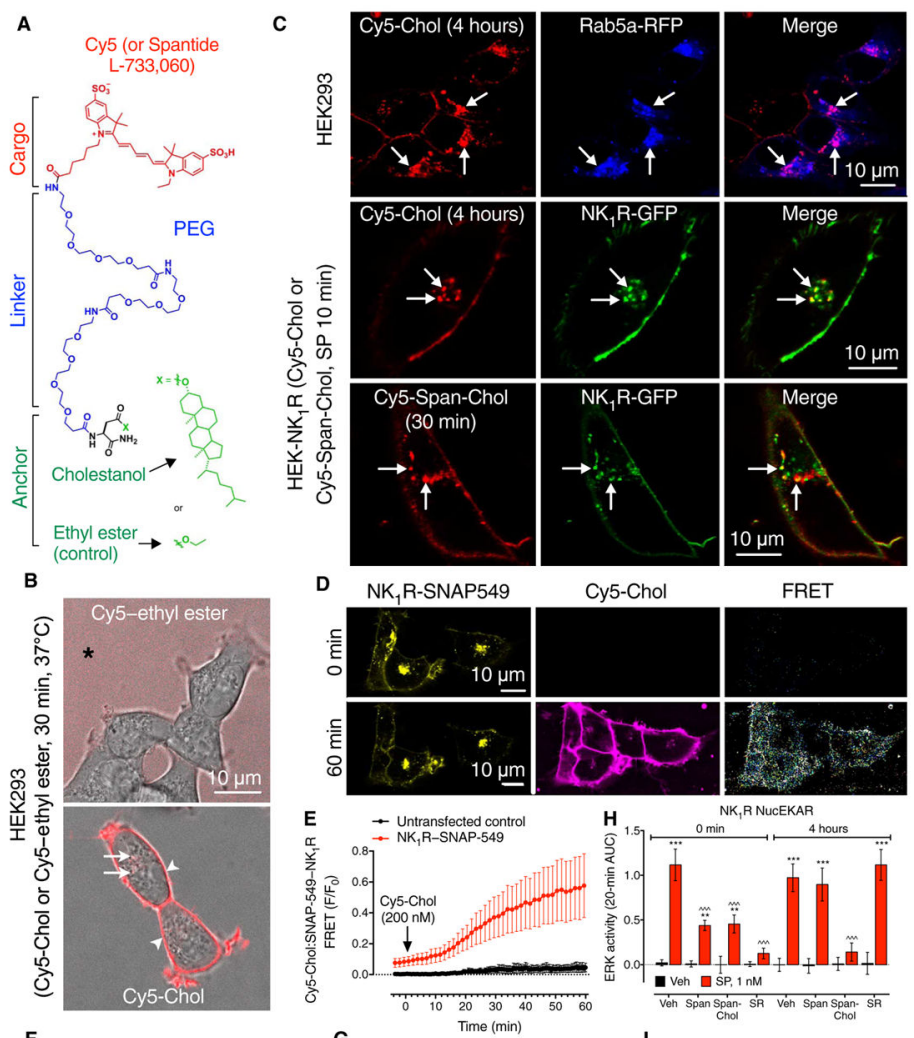

Cy5-Chol

FRET
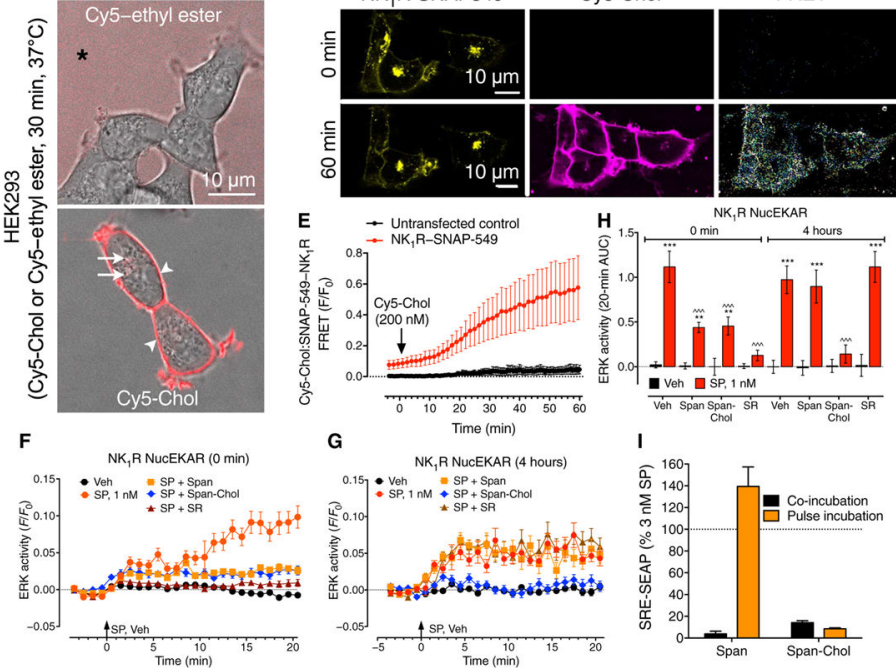

Fig. 6. Antagonism of endosomal $\mathrm{NK}_{1} \mathrm{R}$

(A) Structure of tripartite probes. (B) Cy5-ethyl ester or Cy5-Chol uptake in HEK293 cells.

(C) Cy5-Chol or Cy5-Span-Chol (red) trafficking to RAB5A-red fluorescent protein (RFP)positive (blue) and $\mathrm{NK}_{1} \mathrm{R}-\mathrm{GFP}$-positive (green) endosomes. Asterisk, extracellular; arrowheads, plasma membrane; arrows, endosomes. (D and E) Cy5-Chol:SNAP549-NK ${ }_{1}$ R FRET, indicating localization of SNAP549-NK ${ }_{1} \mathrm{R}, \mathrm{Cy} 5-\mathrm{Chol}$, and FRET signals (D) and time course of FRET in the cytosol (E). Six to nine cells, $n=3$ experiments. (F to H) FRET assays of nuclear ERK activity (NucEKAR) immediately after (0 min) (F) or 4 hours after (4 hours) (G) 30 min of preincubation with Span, Span-Chol, or SR140,333 (SR). (H) AUC of (G). ${ }^{* *} P<0.01, * * * P<0.001$, to vehicle; ${ }^{\wedge \wedge}{ }^{\wedge} P<0.001$, to antagonists. Thirty-one to 417 cells, $n=3$ to 5 experiments. (I) Effects of Span or Span-Chol on SP-induced SRE-SEAP. HEK-NK $\mathrm{N}_{1} \mathrm{R}$ cells were pulse-incubated with Span or Span-Chol for $30 \mathrm{~min}$, washed, recovered for 4 hours, and then stimulated with SP for 20 hours (pulse incubation) or were coincubated with antagonists throughout the experiment (coincubation). $n=3$ experiments. ANOVA, Sidak's test (H). 

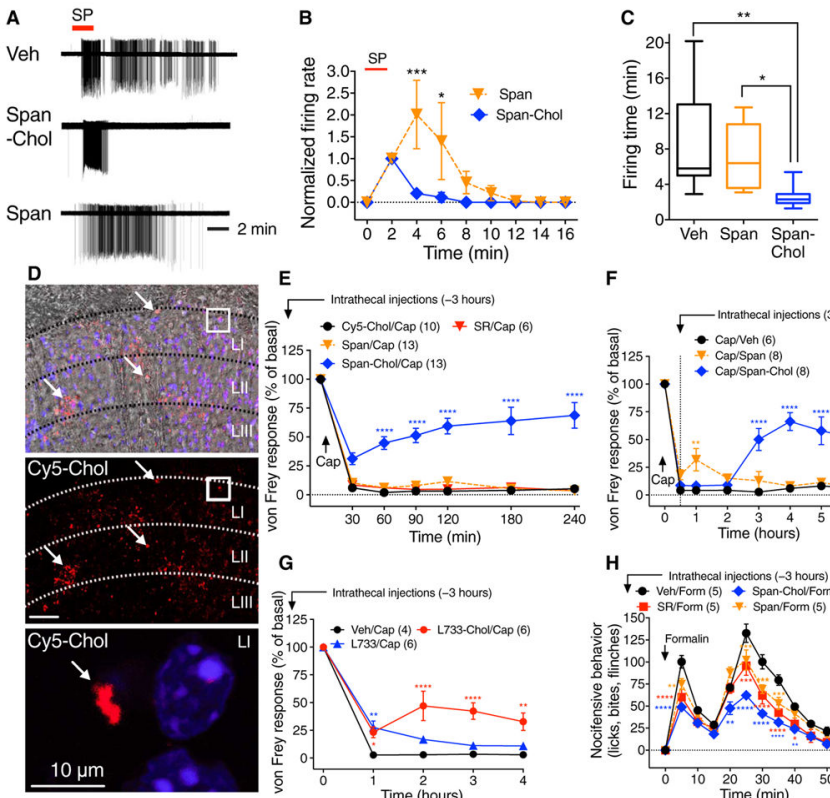

$\mathbf{F}$
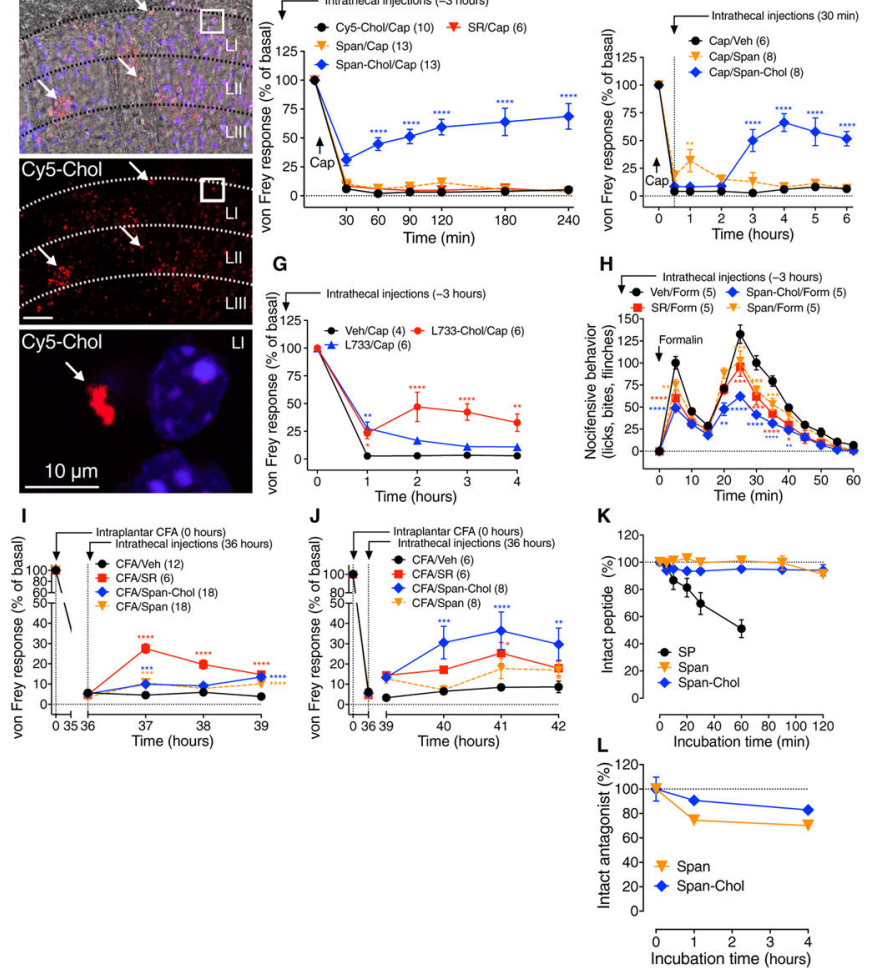

Fig. 7. Antagonism of endosomal $\mathrm{NK}_{1} \mathrm{R}$ in spinal cord slices and in vivo

(A to C) Effects of tripartite antagonists on SP-induced firing of rat spinal neurons. (A) Representative traces. (B) Firing rate normalized to $2 \mathrm{~min}$. (C) Firing duration to last action potential. Six to seven neurons per group from $n=5$ to 18 rats. (D) Localization of Cy5Chol (arrows, red) and DAP (blue) in superficial laminae (L) 6 hours after intrathecal injection in mouse. Top panel shows phase contrast superimposed on a fluorescence image; bottom panels show fluorescence images. White box denotes magnified region. (E to $\mathbf{J})$ Effects of intrathecally administered Cy5-Chol, SR140,333 (SR), Span, Span-Chol, L-733,066 (L733), or L-733,0660-Chol on nociception in mice. (E to G) von Frey withdrawal responses of capsaicin-injected paw. (H) Nocifensive behavior after intraplantar formalin. (I and J) von Frey withdrawal responses of CFA-injected paw. $* P<0.05, * * P<$ $0.01, * * * P<0.001, * * * * P<0.0001$, to control. (K) Kinetics of degradation of SP, Span, and Span-Chol by membranes prepared from mouse spinal cord $(n=3)$. (L) Kinetics of degradation of Span and Span-Chol in human cerebrospinal fluid. $n=2$, mean \pm SD. ANOVA, Sidak's test (B); Dunn's test (C); Dunnett's test (E to J). 


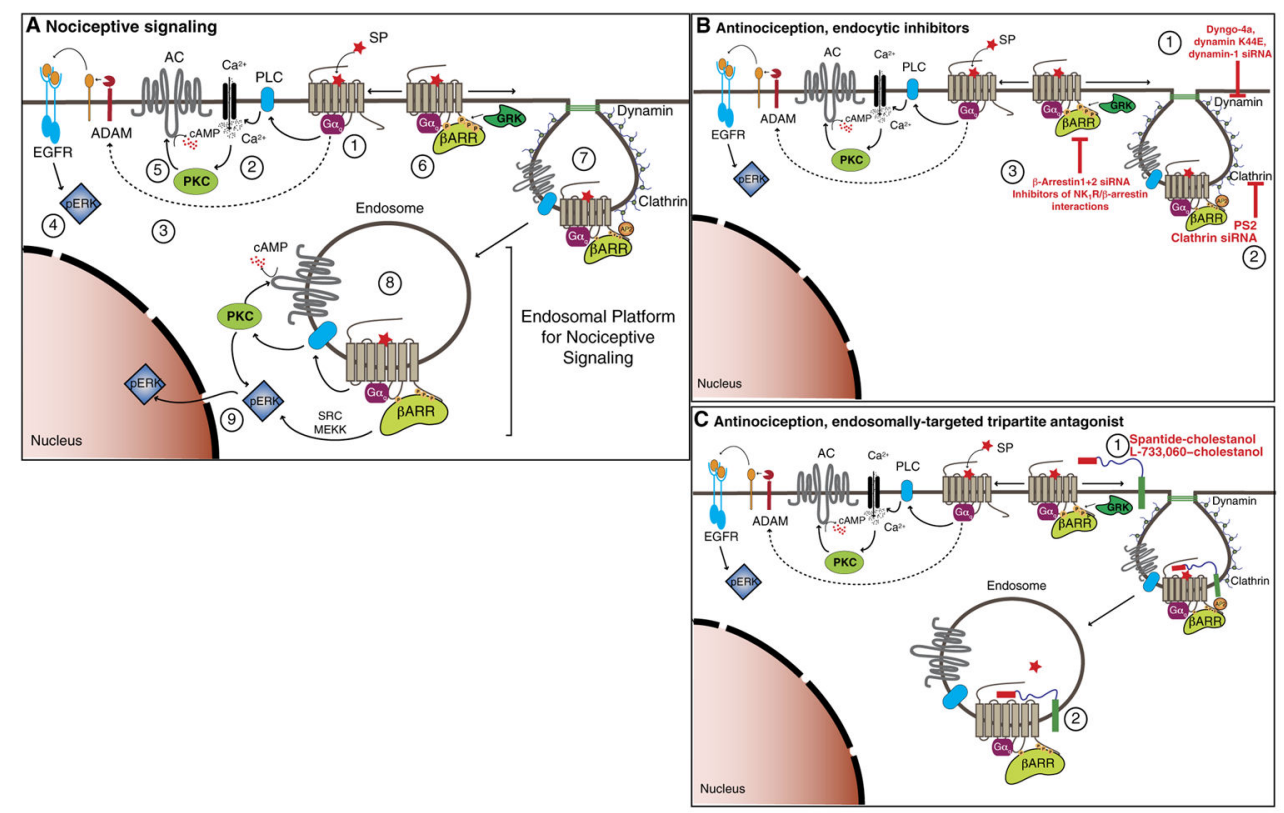

Fig. 8. Endosomal platforms for signaling pain

(A) Nociceptive signaling. $\mathrm{NK}_{1} \mathrm{R}$ couples to $\mathrm{Ga}_{\mathrm{q}}$ (1), PLC-dependent $\mathrm{Ca}^{2+}$ mobilization (2), and a disintegrin and metalloproteinase (ADAM)-dependent epidermal growth factor receptor (EGFR) transactivation (3), which stimulates cytosolic ERK (4). $\mathrm{Ca}^{2+}$ activates $\mathrm{PKC}$, which stimulates adenylyl cyclase (AC) to produce plasma membrane cAMP (5). GRK-phosphorylated $\mathrm{NK}_{1} \mathrm{R}$ interacts with $\beta$ ARRs (6), which scaffold clathrin and adaptor protein 2 (AP2), leading to $\mathrm{SP} / \mathrm{NK}_{1} \mathrm{R}$ endocytosis (7). Endosomal SP/NK $\mathrm{N}_{1} \mathrm{R}$ (8) stimulates cytosolic PKC activity, cytosolic cAMP, and nuclear ERK activity (9), which drive neuronal excitation and nociceptive transmission. (B) Antinociception, endocytic inhibitors. Inhibition of dynamin (1), clathrin (2), or $\beta A R R s$ (3) prevents $\mathrm{SP} / \mathrm{NK}_{1} \mathrm{R}$ endocytosis, endosomal signaling, and nociceptive transmission. (C) Antinociception, tripartite antagonists. Tripartite antagonists incorporate into the plasma membrane (1) and traffic to endosomes (2), where they suppress $\mathrm{SP} / \mathrm{NK}_{1} \mathrm{R}$ nociceptive signaling. 